INSTITUTO DE PSICOLOGIA - UNIVERSIDADE DE SÃO PAULO CARLOS EUGÊNIO DE CARVALHO

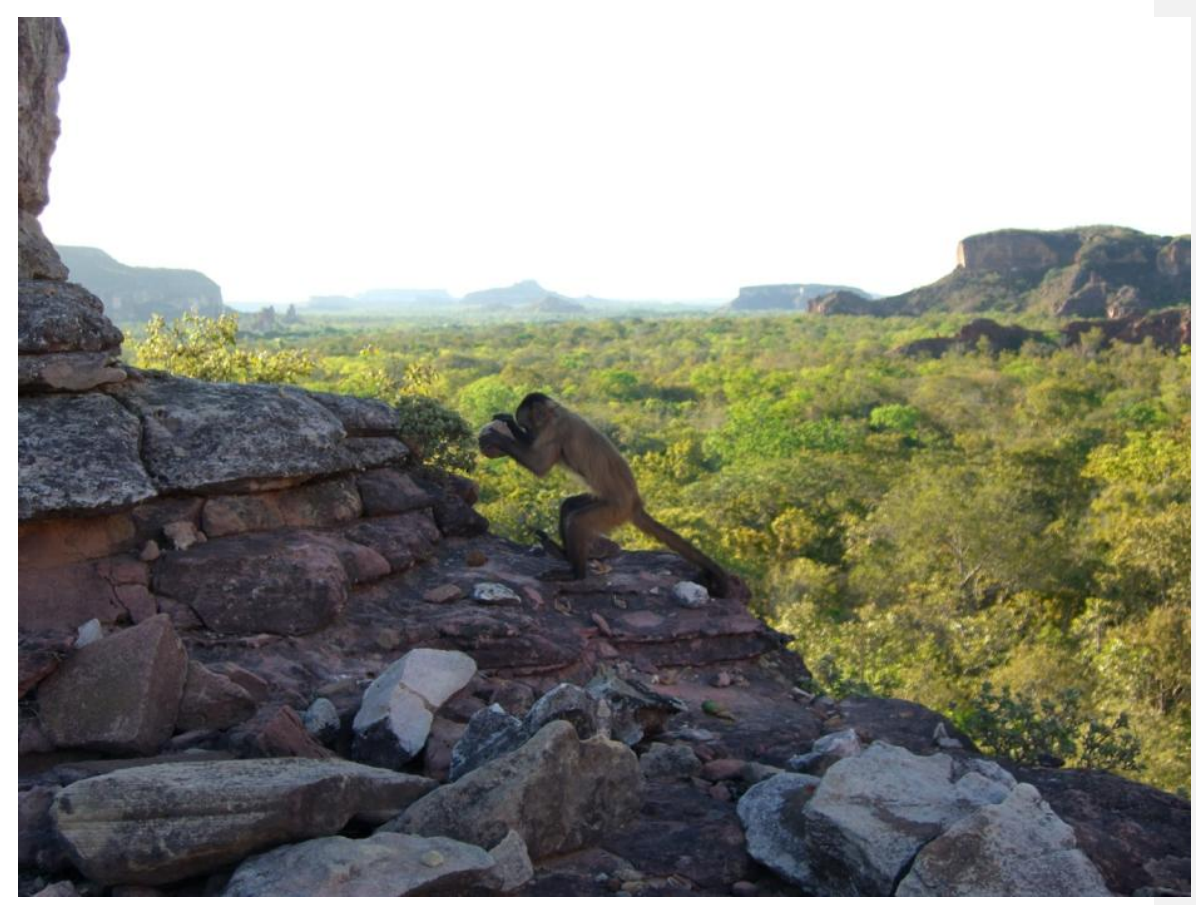

ESTUDO DA MOTIVAÇÃO PARA MANIPULAÇÃO E PARA BRINCADEIRA SOCIAL EM MACACOS-PREGO (SAPAJUS SP.) 
CARLOS EUGÊNIO DE CARVALHO

\section{ESTUDO DA MOTIVAÇÃO PARA MANIPULAÇÃO E PARA BRINCADEIRA SOCIAL EM MACACOS-PREGO (SAPAJUS SP.)}

Dissertação apresentada no Instituto de Psicologia da Universidade de São Paulo para obtenção do título de Mestre em Psicologia

Área de Concentração: Psicologia Experimental

Orientadora: Prof. Dra. Biseida Dôgo de Resende 
CARLOS EUGÊNIO DE CARVALHO

ESTUDO DA MOTIVAÇÃO PARA MANIPULAÇÃO E PARA

BRINCADEIRA SOCIAL EM MACACOS-PREGO (SAPAJUS SP.)

BANCA EXAMINADORA

(Nome e Assinatura)

(Nome e Assinatura)

(Nome e Assinatura)

Dissertação defendida e aprovada em:

São Paulo

2013 


\section{AGRADECIMENTOS}

À Profa. Briseida Dôgo de Resende, Bri, com grande respeito, carinho e admiração, pela fundamental orientação para o desenvolvimento deste trabalho, por suas sugestões, compreensão e pela confiança em mim depositada; À Profa. Patrícia Izar, Pat, com grande respeito e admiração; À Michele Verderane, Mi, com grande respeito e admiração.

Com amor, ao Carlos Roberto, meu pai; à Águeda, minha mãe, em memória; à minha avó paterna, Guiomar e à Lenita, que são minhas outras mães; Aos meus avós maternos, Armando e Nelly, em memória; ao meu avô paterno, Hélcio, em memória; ao João Luiz, meu irmão.

Aos meus tios e tias, primos e primas, que no total são mais de 90 pessoas.

Ao Deivid Ayala, por todo apoio, compreensão e confiança.

À Mara Ceroni, pelo grande apoio psicológico nestes últimos anos.

Aos amigos Adriana Macedo, Alexandre Vessoni, Alice Melges, André Tuon, Andres Ardila, Bruna Paraffine, Camila Coelho, Carine Redigolo, Carlos Francisco, Clara Corat, Danilo Eugênio, Felipe Vieceli, Gabriela Lourenço, Irene Del Val, João Paulo Bortoluci, José Henrique Benedetti, Laura Piai, Lucas Peternelli, Luiz Biondi, Lydia Getschko, Marcelo Espanhol, Marcos Tokuda, Mariana Fogaça, Maria Alice, Mariana Winandy, Marília Jucá,Marina Fernandez, Marina Rillo, Mayron Costa, Natalia Albuquerque, Nathalia Santis, Rachel Ripardo, Ricardo Hartmann, Rodrigo Nunes Xavier, Rosiane Albuquerque.

Aos amigos e alunos da Acepusp, do Cursinho Henfil e do Colégio e Cursinho Anglo de Osasco, Granja Viana, Taboão e Alphaville.

À Maria, Mario, Márcio, Marco, Mara, Marina, Martinha e Júnior Fonseca, a Família "M", pelas sinceras acolhidas e amizade oferecida na Fazenda Boa Vista, durante as duas expedições ao Piauí.

À Vanda Marins e Benadito Prezia, meus padrinhos.

Contamos com o apoio financeiro da FAPESP e CNPq. 


\section{Lista de Tabelas}

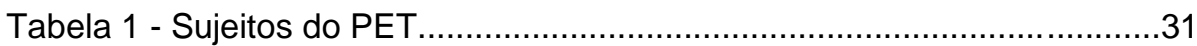

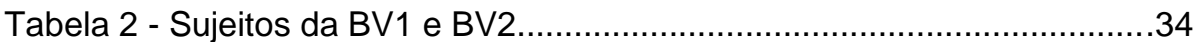

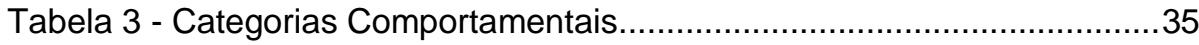

Tabela 4 - Tempo Total de coleta no PET....................................................38

Tabela 5 - Tempo Total de coleta em BV1 e BV2.........................................39

Tabela 6 - Frequências Relativas (1/min) dos comportamentos de cada indivíduo durante as coletas BV1, BV2 e PET ............................................ 40

Tabela 7 - Resultados significativos de testes de correlações não

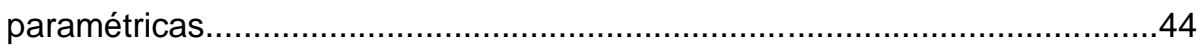




\section{Lista de Figuras:}

Figura 1 - Correlação de Spearman para as variáveis "manipulação" e "brincadeira social" de todos os indivíduos na BV1.

Figura 2 - Correlação de Spearman entre as variáveis "brincadeira social" e "percussão de pedra no coco" no grupo de fêmeas na BV1

Figura 3 - Manipulação: Comparação entre as frequências relativas de BV1 e BV2 .46

Figura 4 - Manipulação em BV1, BV2 e PET ...............................................47

Figura 5 - FR de "quebra de coco proficiente" em BV1 e BV2 .......................48

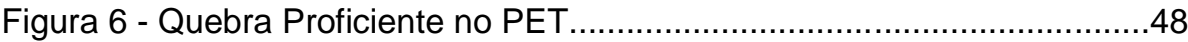

Figura 7 - Percussão de coco em BV1 e BV2 ..............................................49

Figura 8 - Percussão de pedra no coco no

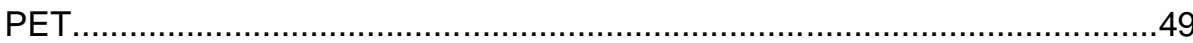

Figura 9 - Brincadeira Social em BV1, BV2 e PET.......................................50 


\section{Lista de Abreviaturas}

M - Machos

F - Fêmeas

BV1 - Fazenda Boa Vista - Estação Seca

BV2 - Fazenda Boa Vista - Estação Chuvosa

FR - Frequência Relativa (1 frequência do comportamento / min)

PET - Parque Ecológico do Tietê 


\section{Resumo}

A Brincadeira e a Manipulação Exploratória ativam o Sistema de Recompensa. Por meio de comportamentos exploratórios, das percepções sensoriais e ações motoras, o animal aprende sobre as propriedades e potencialidades do meio, como anuncia a Teoria da Percepção e Ação. Extrapolamos esse raciocínio para explicar que a aprendizagem acerca do ambiente social dá-se por meio de brincadeiras sociais, que são oportunidades de se explorar, perceber, agir e aprender potencialidades e características sobre outro membro do grupo. Nosso objetivo foi verificar se indivíduos imaturos que manipulam mais são também aqueles que estão mais envolvidos em brincadeiras sociais, por serem mais exploradores em relação a objetos e ao meio social. Nós estudamos dois grupos: um selvagem, na Fazenda Boa Vista (Estado do Piauí, região de Cerrado) em duas estações: um mês de estação seca (11 indivíduos) e um mês de estação chuvosa (12 indivíduos); um grupo semilivre no Parque Ecológico do Tietê, região urbana de São Paulo, capital, por cinco meses (19 indivíduos). Não pudemos estabelecer vínculo direto e universal entre brincadeiras sociais e comportamentos manipulativos, inclusive o de quebra de cocos, em todos os indivíduos. Observamos aumento de brincadeiras sociais e comportamentos manipulativos entre os machos e observamos que machos brincaram mais que fêmeas quando havia maior disponibilidade de alimento. Explorar o meio social gera respostas mais complexas do que explorar o meio físico, portanto, outras habilidades são necessárias para viver em grupo, mas isso não exclui a possibilidade de compartilhamento de motivação para explorar os ambientes físico e social.

Palavras - chave: Sapajus sp., Motivação; Exploração; Manipulação; Brincadeiras Sociais. 


\begin{abstract}
Play and Exploratory Behaviour activate the Rewarding System. By exploratory behaviour, sensory perceptions and motor actions, the animal learn about properties and affordances of the environment, according to the Perception and Action Theory Extrapolating it, we suggest that social play is a means for learning about the social environment because it generates opportunities to explore, perceive, act and learn potentialities and characteristics from conspecifics. Our aim was to verify if immature individuals who manipulate more objects and food are also individuals that are more involved in social play behaviour, because they are more explorative in relation to objects and social surrounding. We studied two groups: a wild one, in Boa Vista Farm (State of Piauí, Brazilian Savanna area), in two seasons: a month in dry season (11 individuals) and a month in wet season (12 individuals); a semi-free ranging troop in Tietê Ecological Park, urban zone of São Paulo City, by five months (19 individuals). We cannot establish a direct and universal link between Social Play and Manipulation, including nut cracking, for all individuals. We observed an increase in social play and manipulative behaviors in males and we observed that males played more than females when there was greater availability of food. The exploration of the social surrounding generates more complexes responses than the exploration of the physical environment, therefore, other skills are necessary to live in social life, but it does not exclude the possibility of shared motivation to explore the physical and social surroundings.
\end{abstract}

Keywords: Sapajus sp., Motivation; Exploration; Manipulation; Social Play. 


\section{INTRODUÇÃO E OBJETIVOS}

Ao considerarmos organismos como sistemas em desenvolvimento, pressupomos que o comportamento realizado pelo indivíduo é construído ao longo de seu desenvolvimento e não transmitido por seus ancestrais de maneira imutável. O sujeito aprende e interfere nos rumos de seu desenvolvimento ao perceber e interagir com componentes físicos e sociais no seu entorno por meio de ações motoras exploratórias e escolhas (Lockman, 2000, 2006; Ridley, 2003; Odling-Smee et al., 2003; Jablonka \& Lamb, 2005; Lewkowicz, 2011; Laland \& O’Brien, 2012; Fragaszy, 2012).

A juventude é um período crítico para aprendizagem e desenvolvimento de habilidades que serão usadas no futuro (Fagen, 1981, Fragaszy et al, 2004b), como habilidades sociais e manipulativas para forrageamento (Joffe, 1997). Por isso é um período em que há grande dedicação a atividades exploratórias e brincadeiras (Pisula, 2008).

Partindo desses pressupostos, estudamos comportamentos manipulativos e brincadeiras sociais em infantes e juvenis de dois grupos de macacos-prego: um grupo selvagem (Sapajus libidinosus), que habita uma região de Cerrado, que sofre processo de desertificação, no Piauí; e um grupo semilivre (Sapajus sp.), que vive em um parque urbano da cidade de São Paulo, a fim de testarmos nossas hipóteses de que há correlação entre comportamentos manipulativos, dentre eles, o de quebra de coco, e brincadeiras sociais entre os indivíduos dos grupos, partindo do pressuposto que a motivação exploratória impulsiona a exploração de objetos por meio de manipulação e impulsiona a exploração do ambiente social por meio de brincadeiras sociais, ambos os comportamentos fundamentais para 0 desenvolvimento cognitivo do animal.

Inicialmente, apresentaremos a perspectiva teórica de aprendizagem por meio da "Percepção e Ação"; em seguida, a abordagem de "Sistemas em desenvolvimento", que destaca o organismo como um sistema que está em constante desenvolvimento e considera o desenvolvimento motor intimamente ligado ao cognitivo; em seguida, falaremos sobre exploração do ambiente por 
meio de manipulação e por meio de brincadeiras sociais e como esses comportamentos são veículos para o organismo perceber, agir e aprender; Por fim, apresentaremos um perfil da espécie objeto deste estudo, os macacos-prego (Sapajus sp.).

\section{A PERCEPÇÃO E AÇÃO}

A Teoria da Percepção e Ação (Lockman, 2000) aborda o tema da Aprendizagem a partir da abordagem ecológica da aprendizagem perceptual e do desenvolvimento (Gibson, 1967; Gibson e Pick, 2000), que considera o ambiente onde o organismo desenvolve seu nicho como fator fundamental para o entendimento de seu desenvolvimento. A Teoria da Percepção e Ação é baseada em estudos sobre desenvolvimento motor que afirmam que os movimentos, além de serem gerados por eferências ou "outputs" do Sistema Nervoso Central que atuam nos músculos, são produtos das propriedades energéticas e biomecânicas do corpo, do ambiente e das exigências de cada tarefa (Lockman e Thelen, 1993). Tais movimentos mecânicos são fundamentais para o organismo perceber e colher informações sobre 0 ambiente, ou seja, aprender sobre ele.

Para Eleanor e James Gibson (1979, 1988, 2001), crianças são exploradoras ativas do ambiente por meio de percepção e ações motoras, eventos considerados indissociáveis. Crianças podem perceber informações do ambiente e agir de maneiras adequadas em situações novas sem que antes tenham tido alguma experiência crítica que pudesse determinar a ação delas no presente frente à novidade. Se uma criança é colocada em contato com um novo brinquedo, ela pode aprender sobre as propriedades do brinquedo e a utilizá-lo de maneira adequada e rítmica após algumas tentativas e erros, sem ter experimentado algum evento crítico prévio que determinasse a ação dela. Sob essa perspectiva, "perceber é experimentar" e após experiências, a criança adquire "proficiência" para utilizar o brinquedo. 
Através da percepção de estímulos do ambiente através da visão, olfato, paladar, tato ou audição, indivíduos em desenvolvimento recolhem informações do ambiente sobre texturas, dimensões, formatos e potencialidades de objetos e de substratos. Obtendo informações do ambiente, o sujeito aprende e progressivamente, por meio de erros e acertos, ele muda seu comportamento. Segundo Lockman $(2000,2006)$, pesquisador da ontogênese do uso de ferramentas por bebês humanos, o desenvolvimento do uso de ferramentas é um processo contínuo, emergente a partir da detecção de objetos e da percepção de suas potencialidades pelo sujeito que realiza interações e diferentes combinações entre os objetos. Por meio de tentativas e erros e através da substituição de uns meios de manipulação por outros, consequentemente, os sujeitos adquirem proficiência no uso de ferramentas.

O comportamento de quebrar coco era considerado uma atividade proveniente de um "insight cognitivo" que o indivíduo teria sobre como certos objetos poderiam ser usados e combinados para alcançar o objetivo (Köhler, 1927), o de quebrar coco, neste caso. Com base nessa proposta para explicar o comportamento de quebra de coco, um chimpanzé perceberia subitamente que poderia quebrar cocos, posicionando-os em superfícies especiais, com um tipo de pedra suficientemente boa (o meio pelo qual procura alcançar 0 objetivo) para quebrar e acessar o endosperma para comê-lo, sem ter passado por experiências graduais de erros e acertos durante tentativas de quebrar e de perceber propriedades e potencialidades físicas do coco. Essa forma de explicar o comportamento pressupõe que o uso de ferramentas seria um salto além das informações que são dadas no presente momento em que o animal usa as ferramentas. Para Bates (1979), o uso de ferramentas requereria a habilidade de haver "representação mental" dos objetos, dos meios e das combinações necessárias para haver uso de ferramentas. A Teoria da Percepção e Ação se distancia desses pontos de vista quando se foca no desenvolvimento do comportamento, nas tentativas e nos erros, nas mudanças graduais das formas de o sujeito manipular os objetos, que 0 levariam à proficiência no uso de ferramentas. Essa abordagem é mais parcimoniosa do que fazer elucubrações sobre representação mental e insight, fenômenos que não são passíveis de medição e de se testar 
hipóteses. Em suma, o uso de ferramentas é compreendido, a partir da perspectiva da Percepção e Ação, como uma extensão de tentativas flexíveis de se explorar e adquirir informações sobre o mundo.

Essa abordagem teórica reconhece o organismo como uma unidade auto-organizada e dinâmica, envolvida com muitos sistemas de organização e complexidade, sejam sistemas neuronal, endócrino, muscular, ósseo, cognitivo, etc. (Lewis, 2000), em que a biodinâmica do desenvolvimento ocorre por meio de uma conexão íntima entre mente e corpo baseada na hipótese de que coordenação motora e controle de ações emergem de contínuas, íntimas e inerentes relações entre o sistema nervoso central e a periferia (Lockman e Thelen, 1993).

Segundo von Hofsten (2009), embora percepção e ação estejam profundamente enraizadas na filogenia, seriam de pequena utilidade se não desenvolvessem. O desenvolvimento é resultado de dois pontos fundamentais que são inseparáveis: o sistema nervoso central e as ações dos sujeitos em desenvolvimento. $O$ cérebro possui sua própria dinâmica que faz neurônios se proliferarem, migrarem e se diferenciarem, de determinadas maneiras em determinados momentos. No entanto, as capacidades que emergem por meio de ações dos indivíduos são modeladas na interação com o ambiente. Desta maneira, a interação dinâmica entre sistema nervoso, outras partes do corpo e o mundo externo fomentam o desenvolvimento do organismo.

O uso da perspectiva da Percepção e Ação vem ganhando espaço dentro da primatologia, em especial no que diz respeito ao estudo de mudanças no comportamento motor ao longo do desenvolvimento da habilidade de usar ferramentas em primatas (Resende, 2004; Visalberghi et al., 2007, 2009a, 2009b; Resende et al., 2008; Fragaszy et al., 2010, 2013; Liu et al., 2011). A abordagem da Percepção e Ação nos faz atentarmos aos processos de percepção que contribuem para o desenvolvimento e melhor desempenho na quebra de coco em várias etapas da aprendizagem do comportamento.

Bril et al. (2009) realizaram um estudo teórico e metodológico, com cinco chimpanzés cativos, com foco na análise de movimentos realizados pelos 
símios para realizar tarefas e na maneira com que os indivíduos ajustavam os movimentos e selecionavam os martelos mais eficientes para quebra em termos de posicionamento, produção e aplicação de energia cinética, análise de trajetórias dos golpes e velocidades aplicadas para realizar a quebra. Os dados coletados revelam que os chimpanzés mobilizaram forças ativas (movimentos musculares) e passivas (energia potencial do sistema, como por exemplo, mudanças na altura em que a pedra é levantada), ou seja, modularam forças dinâmicas do sistema "braços-ferramenta", obtendo melhor desempenho na tarefa.

Resende et al. (2008) estudaram a ontogenia do comportamento de quebra de coco de macacos semilivres, do PET. Puderam observar que a aprendizagem ocorre de maneira progressiva e a partir da exploração das potencialidades dos objetos usados para quebrar cocos, assim como prevê a teoria: a manipulação de um objeto precede a manipulação de dois objetos, que ocorre ocasionalmente, seja entre dois objetos ou um objeto e um substrato que são combinados em contextos de exploração (Fragaszy \& Adams-Curtis, 1991); o golpe simples com coco sobre uma superfície precede a manipulação mais complexa de combinar manipulação do coco, da pedra usada para golpear (martelo) e da pedra usada como superfície (bigorna); os indivíduos realizam ações irrelevantes para a quebra (como empurrar, virar, rolar pedras) antes de realizar ações relevantes (como bater uma pedra contra a outra); primeiramente, os macacos executam combinações variáveis de ações necessárias para se quebrar coco, e depois executam combinações corretas para quebrar cocos; o sucesso de quebra aumentou enquanto a frequência de golpes inadequados diminuiu.

A seleção de ferramentas por animais parece acontecer em decorrência da percepção das potencialidades das mesmas, de tentativas e erros no uso delas, assim como prediz a teoria da Percepção e Ação: Chimpanzés (Pan troglodytes) selecionam pedras que servem como martelo para quebrar cocos de acordo com a resistência do coco a ser quebrado, segundo Boesch \& Boesch (1983); Chimpanzés também manufaturam e usam ferramentas com propriedades específicas para mergulhar no mel e comê-lo e para "pescar" cupins; Macacos Cynomolgus (Macaca fasciculares) usam pedras com 
diferentes formas para martelar (Gumert et al., 2009); Macacos-prego (Sapajus libidinosus), na Fazenda Boa Vista, onde parte deste trabalho foi realizado, selecionam pedras mais pesadas, mesmo de que volume menor em relação à outra mais leve apresentada para quebrar cocos (Visalberghi et al., 2009b), e durante o curso de escolha das pedras, eles tocavam as pedras repetidas vezes com as pontas dos dedos (tapping), como se estivessem obtendo informações sobre as potencialidades da pedra e vendo se servem ou não para quebrar coco; Fragaszy et al. (2010) realizaram um experimento parecido com o citado anteriormente, em que os macacos podiam escolher pedras de diferentes massas, mas com uma diferença de massa menor entre a mais pesada e a mais leve se comparada ao experimento de Visalberghi et al. (2009). Nesse trabalho, obtiveram resultados que mostram que macacosprego discriminam pedras de acordo com a massa no contexto de quebra de coco, selecionando a mais pesada quando podem escolher, e no curso de escolha, bateram outros objetos na pedra, tocavam as pedras repetidas vezes com as pontas dos dedos (tapping) e manusearam a pedra passando-a de uma mão para a outra sem soltá-la, o que sugere que por meio desse comportamento, eles obtêm informações (eles percebem e agem) sobre as potencialidades e propriedades da pedra. Nesse trabalho, observaram também que os macacos-prego preferem quebrar cocos de tucum (Astrocaryum campestre), que são menos resistentes, em vez de Piaçava (Orbignya sp.), que são mais resistentes; Macacos-prego (Sapajus libidinosus) selecionaram covas, pequenas concavidades em substratos onde um coco era apoiado para ser quebrado, que fossem mais efetivas para quebrar cocos (Liu et al., 2011). Media-se a efetividade contando o número de cocos quebrados na determinada cova em 100 marteladas ali dadas; Em um estudo mais recente, a partir dos dados coletados, concluíram que os macacos-prego posicionam cocos de maneira estável e estratégica para quebrá-lo (Fragaszy et al., 2013).

Este trabalho está inserido nesse contexto de pesquisas sobre Sapajus sp., na Fazenda Boa Vista (Projeto Ethocebus) e no PET, sobre a aprendizagem de quebra de cocos, bem como fatores do ambiente e sociais que podem influenciar na aprendizagem, ontogenia de atividades manipulativas, provável seletividade de objetos para quebra, estudo do 
ambiente e necessidades do animal, entre outros, que nosso grupo vem desenvolvendo, sob a ótica da Percepção e Ação. Este trabalho visa suscitar uma discussão sobre a motivação que leva o macaco explorar o ambiente físico e social, buscando testar a hipótese de vínculo entre brincadeira social e atividade exploratória.

\section{SISTEMAS EM DESENVOLVIMENTO}

A abordagem teórica de "Sistemas em desenvolvimento" explica o desenvolvimento humano como produto de mudanças nas relações entre o indivíduo e o ambiente em vários níveis (Gottlieb, 2000; Lerner, 2002), como mencionado anteriormente ao tratarmos da Percepção e Ação, em que sistemas de organização e complexidade, sejam sistemas neuronal, endócrino, muscular, ósseo, cognitivo, etc. (Lewis, 2000) se complementam, havendo reciprocidade nas interações entre o organismo e o meio ambiente, que propiciariam mudanças no comportamento e na forma dos sujeitos, que são sistemas em desenvolvimento (Gabbard, 2008). Ambos os fatores para 0 desenvolvimento, o externo (o meio ambiente explorado pelo sujeito) e o interno (processos cognitivos no Sistema Nervoso Central), são inseparáveis (de Waal, 1999).

As ações são fundamentais para o desenvolvimento cognitivo. Elas são guiadas por informações prévias obtidas sobre percepções e potencialidades do entorno e registradas na memória, sendo fundamentais veículos para o sujeito perceber o ambiente e adquirir informações a seu respeito. As conexões entre percepção de estímulos externos, cognição e motivação promovem interação dinâmica entre o sistema nervoso, desde sua parte central à periférica, e o meio externo (von Hofsten, 2009), promovendo desenvolvimento do ser vivo que explora o ambiente.

Os estudos da evolução do encéfalo primata foram mais pontuados no aumento relativo do neocórtex (Lui et al., 2011; Freckleton et al., 2002), considerado estrutura fundamental para melhor desempenho em habilidades 
motoras, planejamento (Carlson, 2002), para lidar com as complexidades das relações entre indivíduos numa sociedade (Dunbar e Shultz, 2007), negligenciando assim, a importância do aumento do cerebelo (Barton, 2012).

O cerebelo está massivamente interligado ao neocórtex (Leiner, 2010), ao córtex motor, frontal e pré-frontal (Strick et al., 2009). Esse fato demonstra que o cerebelo é estrutura fundamental para controle sensório-motor, aprendizado de habilidades motoras (Habas, 2010), participa de reflexos posturais, movimentos independentes dos membros, equilíbrio, execução de movimentos suaves (Carlson, 2002), memória de procedimento (saber andar, saber dirigir, saber andar de bicicleta), "ensaio mental" (Bellebaum e Daum, 2011), memórias de episódio e de espaço (Leggio el at., 2011), planejamento e tomada de decisões (Ramnani e Miall, 2004). A convergência de estudos de estruturas do encéfalo envolvidas na evolução da capacidade de planejamento, execução de complexas sequências de comportamento, como o uso de ferramentas (Barton, 2012) corrobora a Teoria da Percepção e Ação, ao abordar processos cognitivos como um leque de processos imbricados que medeiam o controle de corpos no ambiente, por meio do que Wilson (2002) chama de "cognição corporeada" (embodied cognition). Dentre esses processos, o processo motor é considerado inferente (um input) no desenvolvimento cognitivo: é veículo para a percepção do ambiente e aquisição de memória e aprendizagem, registradas no Sistema Nervoso Central do indivíduo, agente ativo das ações.

A partir dessas considerações, o processo cognitivo de aprendizagem contrapõe-se à noção anterior de cognição: um conjunto de processos em que neurônios interpretam e integram informações do ambiente e emitem comandos motores para a execução de tarefas, ou seja, o movimento motor era considerado apenas um output do processo cognitivo, apenas uma resposta de um processo "interno" cerebral e não agente fundamental para o desenvolvimento da cognição.

\section{EXPLORAÇÃO DO AMBIENTE POR MEIO DE MANIPULAÇÃO E BRINCADEIRAS SOCIAIS}




\subsection{Exploração}

Exploração, num sentido amplo, é qualquer comportamento que resulta em acúmulo de informações sobre o ambiente (Winkler e Leisler, 1999; Birke e Archer, 1983). Exploração envolve extração ativa de informações do ambiente (Hutt, 1966; Renner, 1990; Stephens, 1993). Animais respondem a novidades investigando-as (Mather e Anderson, 1999), e as respostas eliciadas pelas novidades mudam ou cessam após consecutivas exposições a ela (Baldwin e Baldwin, 1997). Segundo Berlyne (1960, 1966), podemos identificar três categorias exploratórias:

I - Resposta de orientação ou mudança de estado de órgãos de sentido. Por exemplo, um rato, quando exposto a um objeto novo, direciona as narinas a ele e por meio dessa ação, obtém informações sobre a novidade;

II - Resposta locomotora: o animal locomove-se no ambiente para obter informações novas;

III - Respostas investigatórias: o sujeito explorador age sobre o objeto para percebê-lo, por meio de manipulação, por exemplo. Essa será uma categoria comportamental de nosso etograma para investigar exploração.

Berlyne propôs outras duas distinções que abrangem as três citadas anteriormente: a manipulação extrínseca e a intrínseca. A primeira é motivada para saciar necessidades imediatas, como comer, beber, copular; a segunda é um comportamento motivado por curiosidade.

Motivação intrínseca (Barto et al., 2004; Berthier et al., 2005) refere-se a ser movido a fazer algo devido ao prazer que a atividade por si só promove, o que leva organismos a explorar e brincar. Há evidências de que o sistema dopaminérgico de recompensa é ativado em resposta a novidades (Singh et al., 2005), logo, podemos inferir que explorar novidades gera prazer.

Uma importante maneira de explorar é investigar e manipular objetos, que podem servir como comida, material para preparar um local para dormir, predadores, possíveis aliados e potenciais parceiros para cópula (Winkler, H., Leisler. B., 1999). Não é clara a distinção entre explorar um objeto e brincar com ele. Pisula (2008) cita características que ambos os comportamentos têm em comum: 
a) a irregularidade: brincar e explorar são comportamentos que ocorrem de maneira irregular, não cíclica e sem padrões claros;

b) multiplicidade de movimentos locomotores envolvidos para que 0 comportamento ocorra;

c) variedade de estímulos que podem eliciá-los;

d) variedade de estímulos externos que podem interrompê-los;

e) valor adaptativo: ambos são comportamentos que consomem energia no presente sem uma finalidade óbvia de recompensa ou aumento de aptidão reprodutiva, mas que indicam que o valor adaptativo é tardio.

A diferença mais clara, ainda segundo o autor, em relação aos dois comportamentos, é que explorar o ambiente é um comportamento compartilhado por todos os animais, enquanto que brincar não é. Brincar é um comportamento mais recente na história evolutiva dos animais.

Panksepp (1998) sugeriu como emoções primárias as seguintes:

a) O Sistema de Procura (Seeking System), cuja motivação é a busca, a expectativa;

b) O Sistema de Raiva (Rage System), causador de raiva e fúria;

c) O Sistema de Medo (Fear System), causador de medo e ansiedade;

d) O Sistema de motivação para cópula (Lust system);

e) O Sistema de Cuidado (Care System): relacionado à prestação de cuidados e provimentos parentais;

f) O Sistema de Pânico (Panic Systrem): relacionado à resposta de separação, necessidade de cuidados;

g) O Sistema Lúdico (Play System): relacionado ao comportamento de brincar.

Segundo o autor, o Sistema de Procura é generalista em relação aos objetivos de procura. Segundo ele, o sistema mesolímbico dopaminérgico, que se estende a partir da área ventral tegmental do mesencéfalo (VTA midbrain ventral tegmental area), através do hipotálamo lateral ao nucleus accumbens e córtex orbitofrontal, reconhecido amplamente como Sistema de Recompensa, é ativado quando há execução de comportamento exploratório. O sistema dopaminérgico mesolímbico desempenha um papel fundamental na aprendizagem, provavelmente associando a excitação de atividades 
específicas, fixando assim um valor afetivo prazeroso para estas atividades que, então, pode funcionar como uma recompensa para a sua repetição (Wise, 2004), como prevê o condicionamento de Skinner (1953). Os componentes do sistema relacionados ao "querer" e "gostar" são também mediados por opióides endógenos (Peciña, S., 2008) no nucleus accumbens do Sistema de Recompensa, indicando que a estimulação da área promove prazer.

Segundo Panksepp (2011), o "Sistema de Procura" (Appetitive Seeking System) no Sistema Nervoso Central de mamíferos é ativado durante o comportamento exploratório, que pode ser caracterizado por locomoção, pela ação do sujeito cheirar, investigar, explorar objetos com a boca ou com as patas. O "Sistema de Procura" refere-se a uma rede de neurônios que promovem certas habilidades para sobrevivência do organismo ao fazê-lo interessado em explorar o entorno e deixá-lo estimulado quando ele está prestes a ter o que procura, como comida, água, abrigo e cópula. Nos seres humanos, este pode ser um dos principais sistemas cerebrais que geram e sustentam a curiosidade, mesmo para trabalhos intelectuais. Este sistema é bastante eficiente na facilitação da aprendizagem, especialmente aprendizagem sobre informações sobre onde recursos materiais estão situados e a melhor maneira de obtê-los.

Circuitos neuronais críticos para o funcionamento do "Sistema de Procura" estão concentrados no corredor hipotalâmico lateral amplo ("extended lateral hypothalamic corridor"), que responde independentemente de o organismo estar em um estado de necessidade (fome, por exemplo) ou de incentivos no ambiente e permite que o sujeito aprenda sobre eventos do ambiente. Quando a via mesolímbica dopaminérgica é estimulada, o comportamento exploratório é amplificado. A via mesolímbica inicia-se na área tegmental ventral do mesencéfalo e forma conexão com o sistema límbico através do nucleus accumbens, amígdala, hipocampo, e também com o córtex pré-frontal medial.

Quando ratos autoestimulam suas vias mesolímbicas dopaminérgicas (do Sistema de Recompensa), por meio de eletrodos instalados em seus cérebros conectados a aparatos do recinto, que são ativados quando os ratos 
encostam-se a eles, em experimentos descritos por Panksepp (1998), os comportamentos consequentes apresentados por eles é de consecutivas repetições da autoestimulação, indicando haver recompensa (prazer) para o sujeito ao executar o comportamento exploratório.

Doenças do funcionamento da mente, como adição e fissura (craving) por drogas, desordens alimentares e comportamento obsessivo-compulsivo possivelmente (Panksepp, 1998; Panksepp, 2002; Panksepp \& Harro, 2004) estão relacionadas a um funcionamento inadequado do Sistema de Recompensa.

\subsection{Brincadeira Social}

O comportamento de brincar é antigo na história evolutiva de animais, incluindo mamíferos, aves, répteis (Beckoff e Byers, 1998; Fagen, 1981; Leisler e Winkler, 1999; Smith, 1983; Caro, 1988; Burghardt, Ward e Rosscoe, 1996) e até mesmo em polvos - Octopus dofleini - (Mather e Anderson, 1999). Trata-se de um comportamento de fácil identificação e de difícil definição (Beckoff \& Byers, 1998), que contém traços de comportamentos de adultos (comportamentos agressivos, por exemplo), sem consequências imediatas, que pode ocorrer de maneira exagerada, repetitiva e estereotipada, segundo Walters (1987). A brincadeira tem a característica de não ter um ato consumatório (Rasa, 1984), irregular, com variedade de movimentos e que podem ser interrompidos ou estimulados por diferentes estímulos (Pisula, 2008).

Brincadeiras podem ser classificadas como: brincadeira social, estilo que envolve a participação de outros indivíduos, e solitária, que se subdivide em brincadeira com objeto (podendo ser considerado um comportamento exploratório - Rasa, 1984) e brincadeira locomotora (Suomi e Paukner, 2008; Burghart, 1998; Walters, 1987). A brincadeira social envolve pelo menos dois sujeitos (Walters, 1987, Bulghart, 1998) que interagem sem haver agressão; Brincadeira com objetos é aquela na qual o sujeito manipula algum objeto de 
maneira repetitiva, estereotipada sem comê-lo ou prepará-lo para comer. Por fim, a brincadeira locomotora acontece quando o animal pula ou corre sozinho, fazendo movimentos repetitivos, podendo ser exagerados. Brincar é característico da juventude e é observado com muito menor frequência em adultos (Fagen, 1981; Pellis e Pellis, 2007; Pisula, 2008). Como os humanos, outros primatas têm um período de imaturidade estendido, o que é crucial para que aprendam a viver em sociedades complexas e desenvolver habilidades que poderão permitir maior sucesso reprodutivo, e nesse sentido, brincadeiras e outras atividades sociais na juventude podem ser veículos de aprendizagem de habilidades (Fagen, 1981; Smith, 1983; Martin \& Caro, 1985; Pereira e Altmann, 1985; Caro, 1988; Bekoff \& Byers, 1992; Fairbanks, 1993; Biben, 1998; Fragaszy et al., 2004b;) úteis para a vida adulta.

Apesar de haver custos imediatos de brincar, em termos de gastos de energia, exposição ao risco de injúrias físicas e ao de predação, é sugerido que a brincadeira tenha um papel positivo muito significativo na sobrevivência dos primatas (Fagen, 1981).

O estabelecimento de laços sociais em primatas pode se dar durante as brincadeiras (Walters, 1987; Poirier \& Smith, 1974). Em certas espécies, machos são mais interessados em brincadeiras turbulentas, que podem aumentar seu sucesso reprodutivo, ao aumentar habilidades físicas e de luta (Fagen, 1981). Biben (1989), trabalhando com micos- de- cheiro (Saimiri sciureus), apresentou resultados que demonstraram correlação entre papéis de dominância e subordinação em brincadeiras turbulentas e posições hierárquicas na fase adulta. Brincar envolve aprendizado de regras e papéis sociais (Poirier \& Smith, 1974; Bekoff \& Byers, 1998; Brosnan, 2006; Keltner, 2006). De acordo com a hipótese de treinamento motor, proposta por Byers \& Walker, 1995, brincadeiras servem como meio de treinar e refinar habilidades que têm benefício imediato ou tardio para a fisiologia do indivíduo. Segundo os autores, em ratos, camundongos e gatos, a faixa etária em que os juvenis mais brincaram coincidiu com o período crítico para a formação de sinapses no cerebelo e para a diferenciação de neurônios motores, indicando que os benefícios podem ser permanentes. Esses resultados corroboram a abordagem teórica de Sistemas em Desenvolvimento, tratada anteriormente, 
que enfatiza a imbricação entre desenvolvimento motor e desenvolvimento cognitivo.

O treino motor na juventude desenvolveria melhor desempenho motor na posterioridade por propiciar desenvolvimento muscular, ósseo, do tecido conjuntivo, nervoso central e periférico (Brownlee, 1954; Smith, 1983; Martin \& Caro, 1985; Caro, 1988; Bekoff \& Byers, 1992; Fagen, 1993; Biben, 1998). Brincadeiras com objetos possibilitaria treino motor com vários benefícios fisiológicos (Hall, 1998). O maior problema para a aceitação da hipótese do treinamento motor é que correlação entre maior frequência de brincadeiras, formação de sinapses no cerebelo e diferenciação de neurônios motores nada diz sobre causalidade (Pellis, Pellis e Bell, 2010).

Brownlee (1954) faz propôs que a função da brincadeira seria proporcionar a modificação do desenvolvimento muscular. A argumentação usada foi a de que durante a juventude, a musculatura usada em comportamentos raros e vitais, na fase adulta, como lutas e fugas não receberia uso suficiente para se desenvolver adequadamente. Ele chamou os músculos envolvidos nesses comportamentos de "músculos da brincadeira". Essa foi uma hipótese não testada, todavia, iniciou trabalhos mais profundos sobre o desenvolvimento, a partir da experiência, de músculos envolvidos em comportamentos adultos citados anteriormente, que propuseram que a brincadeira serviria como exercício, "treino físico" (Fagen, 1981), ou "prática" (Smith, 1983). Segundo Beckoff e Alen (1998), corroborar as hipóteses é difícil já que as vantagens reprodutivas podem ocorrer tão mais tarde na vida do indivíduo.

Além de haver correlação entre maior frequência de brincadeiras e maturação de sinapses no cerebelo em juvenis (assunto desenvolvido acima), segundo Panksepp (2011), o diencéfalo dorso-medial, área parafascicular e núcleo talâmico posterior são regiões do Sistema Nervoso Central envolvidas no controle de comportamentos lúdicos. $O$ autor também enfatiza que mais pesquisas são necessárias a fim de se compreender melhor o "Sistema lúdico".

Em relação ao "Sistema Lúdico", proposto por Panksepp, a tendência de animais brincarem é parte da preparação para busca por comidas e 
aprendizagem de regras sociais, segundo Toronchuk \& Ellis (2012), podendo esse sistema ser considerado um programa emocional básico na linhagem ancestral de humanos e necessário para o desenvolvimento cognitivo de um infante.

\section{O GÊNERO SAPAJUS}

Os macacos-prego são espécies distribuídas amplamente pela América do Sul. O nome "macaco-prego" é o nome comum dado aos primatas do gênero Sapajus (Rylands et al., 2000; Lynch Alfaro et al., 2012). Eles estão inseridos na família dos Cebídeos (Reeder et al., 2005), junto com espécies dos gêneros Cebus (caiararas), Saimiri (micos-de-cheiro), Leontopithecus (micos-leões), Saguinus (saguis), Callimico (saguis-goeldi) e Callithrix (saguis).

Até recentemente, eram macacos pertencentes ao gênero Cebus e dividiam espaço na classificação com os caiararas, outros primatas presentes na região da Amazônia e na América Central. A partir de análises morfológicas, de sequenciamento do material genético dessas espécies, do estudo da distribuição geográfica, de estudos comportamentais e revisões sistemáticas, os gêneros Cebus e Sapajus têm sido considerados distintos (Lynch Alfaro et al., 2011).

A reconstrução filogenética da história evolutiva dessas espécies sugere que as linhagens que deram origem a Cebus e a Sapajus se separaram há mais de 6,15 milhões de anos, possivelmente devido à formação do Rio Amazonas no fim do Mioceno e se diversificaram no Plioceno (Rylands et al., 2000; Lynch Alfaro et al., 2012).

Eles são animais que possuem um tufo de pelos eretos no alto da cabeça, são de porte médio, corpo robusto e cauda semi-preênsil. Possuem uma coloração com tons entre amarelo e marrom, com tons mais escuros nos membros, cauda e no topete, podendo chegar à coloração preta, que varia de acordo com a espécie. Há evidências que mostram diferenças entre machos e 
fêmeas em relação ao tamanho do corpo, sendo o macho maior que a fêmea (Napier e Napier, 1967; Fleagle, 1999). Os machos adultos possuem testículos e um pênis com cartilagem (Fragaszy et al., 2004b) que tem o formato de um prego quando ereto, o que deu origem ao nome "macacoprego", bem visíveis e as fêmeas possuem um clitóris que se torna mais robusto e curto com o passar do tempo. Infantes podem confundir pesquisadores ao tentar diferenciá-los quanto ao sexo por não terem os testículos visíveis e uma genitália pequena.

São primatas arborícolas e que usam o solo com frequência, dependendo da espécie e do habitat, têm hábito diurno, são-frugívoros, folívoros, insetívoros (Fleagle, 1999), comem brotos, sementes e alguns vertebrados pequenos (Ferreira et al., 2002; Resende et al., 2003; Izar, 2004). Macacos-prego podem detectar informações sobre a densidade de objetos quando os tocam repetidas vezes com as pontas dos dedos (tapping) enquanto forrageiam, o que permite que eles encontrem possíveis presas em galhos mortos (Fragaszy, 1986).

Há grande tolerância de adultos para com os infantes e juvenis, as fêmeas são filopátricas (Izar, 1994; Resende, 2003; Fragaszy et al., 2004b; Verderane, 2005; Verderane, 2010), a estrutura social é "multimacho / multifêmea" (Terborgh, 1983, Fragaszy et al., 2004b) e a composição do grupo varia de 3 a 30 (Lynch \& Rímoli, 2000) ou de 3 a 40 indivíduos (Freese e Oppenheimer, 1981).

Eles passam a maior parte do tempo forrageando, se locomovendo, descansando e envolvidos em atividades sociais, como catação ou grooming, brincadeiras, cuidados de infantes e comportamentos agonísticos (Fragaszy, 1986, 2004b; Resende, 2004; Izar, 2004; Verderane, 2010; Winandy, 2012).

Espécies do gênero Sapajus têm distribuição geográfica desde a América Central até a Argentina. Indivíduos da espécie Sapajus libidinosus, estudada em um dos grupos deste trabalho, estão distribuídos majoritariamente nas regiões Nordeste e Centro-oeste do Brasil (Fragaszy et al., 2004b).

Como outros primatas, macacos-prego contam principalmente com as mãos para procurar, pegar alimentos e processá-los (Tomasello \& Call, 1997). 
Macacos-prego são grandes exploradores do ambiente. São primatas com grande motivação para interagir com ambiente através de contato físico com objetos e com substratos. Para fazê-lo, eles podem usar as mãos, os pés, o rabo, a boca, de maneiras diversas. Podem transportar um objeto com o rabo enquanto se locomovem e usar as mãos e a boca para explorar e manipular outros. Podem manipular objetos de maneira inovadora e usar objetos como ferramentas (uso de objetos como uma extensão funcional do corpo) para alcançar objetivos imediatos (Fragaszy et al., 2004b). Enquanto infantes, os macacos-prego permanecem a maior parte do tempo em constante contato com suas mães, até o segundo ou terceiro mês, quando eles começam a se separar e explorar o ambiente com maior autonomia (Izar, 1994; Verderane, 2005). Filhotes de mães que não se movimentam muito passam a explorar mais o ambiente, e os de mães mais ativas, têm menos oportunidades, já que são carregados por elas (Byrne e Suomi, 1998).

Infantes em cativeiro, aos seis meses exibem todas as formas básicas de manipulação vistas num adulto, incluindo agarrar objetos com os dedos polegar e indicador (Fragaszy \& Adams-Curtis, 1997). Manipular objetos com as mãos transferindo-os de uma mão a outra é observado a partir de oito semanas e combinar objetos e superfícies viraram comuns aos seis meses (Fragaszy e Adams-Curtis, 1991, 1997). Juvenis entre um e três anos manipulam objetos (13 a 39 meses) mais que os outros (Byrne e Suomi, 1996; Fragaszy e Adams-Curtis, 1991).

Os jovens dedicam significativamente mais tempo ao forrageamento que adultos e infantes (Fragaszy et al., 2004b; Resende, 2004, Resende et al., 2008; Winandy, 2012), o que pode ser explicado por terem menos competência no forrageamento devido ao menor tamanho, menor força e menor experiência (Janson \& van Schaik, 1993); e demonstram maior generalidade de manipulação (Fragaszy \& Adams-Curtis, 1991).

Algumas populações livres e semilivres usam rotineiramente ferramentas de forma espontânea (Mannu \& Ottoni, 2001; Fragaszy et al, 2004a; Moura \& Lee, 2004; Resende, 2004; Ottoni et al., 2005; Waga et al., 2006; Resende et al, 2008; Ottoni \& Izar, 2008; Mannu \& Ottoni, 2009; Spagnoletti et al., 2011) para quebrar cocos. Os indivíduos usam pedras como um martelo para 
golpear cocos posicionados sobre uma superfície, chamada de bigorna. A quebra de coco é uma atividade em que o animal utiliza as duas mãos, adota postura bípede para realizar movimentos percussivos da pedra sobre um coco posicionado em uma bigorna. Essa parece ser uma atividade que ocorre de maneira oportunística (Spagnoletti et al., 2012), ou seja, eles quebram cocos quando os encontram e não os quebram devido à escassez de alimentos, outra proposta para explicar a emersão do comportamento (Moura \& Lee, 2004).

Há indícios de que a quebra de coco ocorra por meio de aprendizagem social, por meio da observação que um indivíduo menos proficiente faz sobre a ação de quebra de coco realizada por outro indivíduo mais proficiente, da descoberta progressiva das potencialidades de objetos do ambiente, por meio de contato com objetos deixados por outros indivíduos que quebraram coco, chamado de realce de estímulo ou stimulus enhancement (Fragaszy et al., 2004; Resende, 2004; Ottoni et al., 2005; Resende et al., 2008; Coelho, 2009).

Apesar de haver risco de injúrias durante a quebra de coco, principalmente quando não se é proficiente, de haver o risco de atrair predadores devido ao barulho que a atividade gera e apesar de ser uma atividade em que o sujeito fica mais vulnerável a predadores e apesar de haver alto custo energético para animais de 2 a 4 kg (Liu et al., 2009; Fragaszy et al., 2010) levantarem pedras de aproximadamente $1 \mathrm{~kg}$ para quebrar cocos (Fragaszy et al, 2004a; Visalberghi et al., 2007), a atividade de quebra de coco é recompensadora em termos energéticos e de a atividade poder ser lúdica.

Brincadeira social é típica de imaturos, promove proximidade social entre indivíduos da mesma idade, principalmente entre jovens (Resende, 2004). Macacos-prego machos jovens brincam mais que fêmeas (Welker et al., 1989; Izar, 1994; Resende e Ottoni, 2002; Resende, 2004; Fragaszy et al, 2004b; Suomi e Paukner, 2008; Verderane, 2010; Winandy, 2012.) e brincam mais em cativeiro do que em ambiente selvagem (Fragaszy, 2004b), onde passam mais tempo se locomovendo. 
O desenvolvimento do comportamento lúdico foi descrito em vários estudos (Fragaszy, 1989; Fragaszy et al., 1991; Byrne \& Suomi, 1998). Os infantes se engajam em brincadeiras locomotoras e com objetos com oito semanas de vida (Fragaszy et al., 1991) e com 12 semanas, os primeiros episódios de brincadeira social são observados (Fragaszy, 1989).

Macacos-prego frequentemente manipulam objetos de modo que pode ser interpretado como lúdico, como batê-los de maneira percussiva no chão, esfregando-os nas palmas das mãos, podendo ser atividades recompensadoras per se (Fragaszy, 1989; Fragaszy et al., 1991; Byrne \& Suomi, 1998).

\section{OBJETIVOS ESPECÍFICOS}

Nossa hipótese de trabalho é que motivação para explorar impulsiona a exploração de objetos e impulsiona exploração do ambiente social por meio de brincadeira social. Partindo dessa premissa, nossos objetivos específicos são testar as seguintes hipóteses:

A) "Exploração de objetos" (categoria "manipulação" no etograma) e "brincadeira social" são comportamentos que se correlacionam por terem a mesma motivação: a exploratória;

B) Sujeitos que têm desempenho melhor em atividades de quebra de coco (medidas por meio das variáveis "percussão de pedra sobre o coco" e "quebra proficiente") são aqueles que exploram mais o ambiente através de manipulação e brincadeira social.

Prevemos que indivíduos que manipulam mais são aqueles que mais se envolvem em brincadeiras sociais e que, por terem maior motivação para tais comportamentos exploratórios, seriam os que mais quebram coco, pois seriam os mais curiosos para explorar objetos e suas potencialidades. 


\section{METODOLOGIA}

\section{1 ÁREAS DE ESTUDO, SUJEITOS E COLETA DE DADOS:}

\subsection{PET}

Um grupo estudado vive em semiliberdade no PET, que tem uma área verde preservada de $200.000 \mathrm{~m}^{2}$ e é uma reserva ambiental do Estado de São Paulo. Localiza-se na Zona Leste do município de São Paulo, SP.

O Parque promove trabalhos com educação ambiental, é aberto para visitação e lazer da população e tem seu papel de preservação da várzea do Rio Tietê, além de recepção de animais silvestres apreendidos pelo lbama, Polícia Florestal ou doados pela população.

Os macacos-prego estudados vivem soltos nas dependências do parque e recebem alimentos diariamente dos tratadores, além de poderem forragear livremente pelo parque e obter alimentos como folhas, certos frutos, aves e mamíferos pequenos (Ferreira et al., 2002; Resende et al., 2003), insetos, anfíbios e larvas. O grupo é habituado à presença de observadores, já que pesquisadores têm o estudado desde 1995 e funcionários e grupos escolares com guias frequentemente transitam nas áreas mais frequentadas pelos macacos, onde é necessária autorização para entrar, o CRAS (Centro de Recepção de Animais Silvestres).

A vegetação é composta por áreas de mata nativa e de reflorestamento, sendo predominantemente do tipo arbustiva. Existem três lagos e algumas ilhas com outros grupos de macacos no parque. Existem eucaliptos pelo parque, algumas árvores frutíferas, como laranjeiras (Citrus sinensis), amoreiras (Morus nigra), goiabeiras (Psidium guayava), que quando estão frutíferas, servem de alimento aos macacos; e palmeiras jerivá (Syagrus romanzoffiana), produtoras de cocos, os quais os macacos quebram com 
frequência - com o uso de ferramentas, para acessarem e comerem o endosperma.

A coleta dos dados no PET foi feita de Agosto a Dezembro de 2011. O número de indivíduos do grupo variou de 37 a 36 . Os sujeitos eram infantes e juvenis (machos e fêmeas), cujo número variou de 19 a 18. A Tabela 1 apresenta os sujeitos focais, o sexo e a idade deles:

Tabela 1: Sujeitos do PET

Nome, sexo, faixa etária e idade dos macacos no PET. Idade do indivíduo no período de coleta em meses.

\begin{tabular}{|l|l|l|l|}
\hline \multicolumn{2}{|l|}{ SUJEITOS DO PET } & \multicolumn{2}{l|}{} \\
\hline Nome & Sexo & Faixa Etária & Idade (meses) \\
\hline Açúcar & Macho & Infante & $5-10$ \\
\hline Café & Macho & Infante & $5,5-10,5$ \\
\hline Buli & Macho & Infante & $6-11$ \\
\hline Vegan & Macho & Infante & $6-8^{*}$ \\
\hline Didi & Macho & Infante & $7-12$ \\
\hline Franja & Macho & Infante & $9-14$ \\
\hline Morango & Macho & Infante & $9-14$ \\
\hline Careca & Macho & Juvenil & $17-22$ \\
\hline Vodca & Macho & Juvenil & $20,5-25,5$ \\
\hline Floyd & Macho & Juvenil & $30,5-35,5$ \\
\hline Frapê & Macho & Juvenil & $31,5-36,5$ \\
\hline Caju & Macho & Juvenil & $34-39$ \\
\hline Acácio & Macho & Juvenil & $42-47$ \\
\hline Gorila & Fêmea & Juvenil & $20,5-25,5$ \\
\hline Val & Fêmea & Juvenil & $34-39$ \\
\hline Flor & Fêmea & Juvenil & $41-46$ \\
\hline Cuca & Fêmea & Juvenil & $45,5-50,5$ \\
\hline Fritz & Juvenil & $52,5-57,5$ \\
\hline Alice & Juvenil & \\
\hline & Fêmea & 61,5 \\
\hline
\end{tabular}

* Indivíduo morreu durante o segundo mês de coleta 
As faixas etárias dos sujeitos foram determinadas segundo os seguintes critérios utilizados por Resende (2004):

a) Infantes - a partir do nascimento até a independência da mãe. Os indivíduos independentes são os que não são mais transportados por outros sujeitos e não mamam mais;

b) Juvenis - Fêmeas: desde a independência até a maturidade sexual. Caso a fêmea tenha um filhote, ela é considerada juvenil até três meses antes, o período estimado de gestação (Nowak, 1999); Machos: Indivíduos que já são independentes das mães e ainda não completaram seis anos. $A$ idade é utilizada por não sabermos quando o macho atinge a maturidade sexual;

\section{1. 1 Coleta de dados}

A coleta de dados, realizada pela metodologia Animal Focal (Altmann, 1974) foi feita com o auxílio de gravador de voz. O tempo de coleta de cada sessão era de 10', mas episódios acima de oito', em que o focal era perdido de vista por mais de dois', também foram considerados e usados para a análise dos dados. Durante cada sessão de coleta, seguíamos o animal focal e registrávamos os comportamentos que ele realizava de acordo com 0 etograma.

\section{$1.2 \mathrm{BV}$}

A Fazenda Boa Vista (BV) está no município de Gilbués, no Estado do Piauí. Segundo o IBGE (Instituto Brasileiro de Geografia e Estatísticas), a população estimada em 2004 era de mais de 10.000 habitantes. A região está inserida num bioma de Cerrado e vem sofrendo intenso processo de 
desertificação (Sales, 2003; Silva et al., 2009; Crespai, 2008), por isso, tratase de uma região de Cerrado com características de Caatinga.

A região de Cerrado, ou Savana brasileira, é uma formação de área tropical com duas estações bem definidas: inverno seco e verão chuvoso. A vegetação é caracterizada, principalmente, por arbustos, árvores de epiderme grossa e caules retorcidos, folhas recobertas de tracomas e outras adaptações das plantas para clima seco com períodos de queimadas.

A fauna local é muito rica, é constituída, por exemplo, por mamíferos de pequeno e médio porte, várias espécies de aves de rapina, pássaros, e de répteis.

Os indivíduos estudados são primatas da espécie Sapajus libidinosus. O grupo "Chico" (nome do macho alfa do grupo) era composto por 20 animais, na época da coleta inicial, sendo 11 deles imaturos -8 juvenis e três infantes, e 21 animais na segunda coleta de dados.

Esse grupo de macacos-prego está habituado aos pesquisadores, pois vem sendo estudado desde 2005 por pesquisadores vinculados ao Projeto EthoCebus (www.ethocebus.net), uma parceria sólida entre pesquisadores da Universidade de São Paulo (Brasil), Universidade da Geórgia e Universidade do Kansas (EUA) e do Instituto de Ciências e Tecnologia da Cognição (Itália).

\subsubsection{BV1}

A primeira expedição foi feita durante o mês de Julho de 2011, no período de inverno e seca. Durante a rotina de coleta, o grupo de animais foi provisionado com milhos, cocos e bananas. Os animais permaneciam a maior parte do tempo no "Esconderijo", um local próximo à casa da Fazenda, onde se tem uma estrutura montada para guardar equipamentos e vários sítios de quebra de coco próximos a um paredão rochoso, onde experimentos são realizados. 


\subsubsection{Coleta de dados e concordância entre os observadores}

A coleta de dados por meio da metodologia Animal Focal foi feita com o uso de aparelho portátil coletor de dados, o Observer. Cada sessão durava 20 min. As coletas foram feitas pela manhã até o meio das tardes. A escolha dos macacos alvos da coleta de dados foi feita dando prioridade ao sujeito que possuía menor quantidade de focais. Fizemos a concordância entre os observadores e o índice de confiabilidade entre os dados coletados foi maior ou igual a 0,7 (Teste Kappa de Cohen).

\subsubsection{BV2}

A segunda expedição se deu a partir do meio do mês de Janeiro e foi até o meio do mês de Fevereiro de 2012, durante a estação chuvosa. Durante esse período, os animais percorreram uma extensão maior do território do que em Julho de 2011, devido a diversas árvores em época de frutificação e variadas fontes de alimento, afastando-se do "Esconderijo".

Os animais apareciam raramente no "Esconderijo", e quando apareciam, permaneciam por pouco tempo, mesmo quando lhes era oferecidas comidas, como bananas e milhos. Não foram oferecidos cocos aos macacos como da primeira vez. $O$ trabalho de campo foi realizado com os mesmos aparelhos de campo do Observer (Noldus). A Tabela 2 mostra os indivíduos da coleta:

Tabela 2 - Sujeitos da BV1 e BV2

Nome, sexo, faixa etária e idade dos macacos da BV1 e BV2. Idade do indivíduo no período de coleta em meses.

\begin{tabular}{|l|l|l|l|l|}
\hline \multicolumn{6}{|l|}{ SUJEITOS DA BV1 E BV2 } \\
\hline Nome & Sexo & Faixa Etária & Idade em BV 1 & Idade em BV 2 \\
\hline Didi $^{*}$ & Macho & Infante & ----- & $3-4$ \\
\hline Presente & Macho & Infante & $3-4$ & $9-10$ \\
\hline Coco & Macho & Juvenil & $23,5-24,5$ & $29,5-30,5$ \\
\hline Pati & Macho & Juvenil & $43-44$ & $49-50$ \\
\hline
\end{tabular}




\begin{tabular}{|l|l|l|l|l|}
\hline Cangaceiro & Macho & Juvenil & $45-46$ & $51-52$ \\
\hline Catu & Macho & Juvenil & $53-54$ & $59-60$ \\
\hline Tomate & Macho & Juvenil & $55-56$ & $61-62$ \\
\hline Chani & Fêmea & Infante & $5-6$ & $11-12$ \\
\hline Thaís & Fêmea & Infante & $8-9$ & $14-15$ \\
\hline Paçoca & Fêmea & Juvenil & \pm 36 & \pm 42 \\
\hline Pamonha & Fêmea & Juvenil & \pm 36 & \pm 42 \\
\hline Doree & Fêmea & Juvenil & $44-45$ & $50-51$ \\
\hline
\end{tabular}

* Sujeito nascido entre a primeira e a segunda coleta

\section{ANÁLISE DE DADOS}

Usamos as variáveis "manipulação", "percussão de pedra sobre coco" e "quebra proficiente" para tratarmos de comportamentos manipulativos e "brincadeira social".

A tabela a seguir resume as variáveis que usamos:

Tabela 3 - Categorias comportamentais

\begin{tabular}{|c|c|}
\hline \multicolumn{2}{|c|}{ CATEGORIAS COMPORTAMENTAIS } \\
\hline $\begin{array}{l}\text { Categorias } \\
\text { comportamentais }\end{array}$ & Descrição do comportamento \\
\hline Manipulação & $\begin{array}{l}\text { Manipulação com patas dianteiras ou traseiras, rabo ou boca para } \\
\text { exploração de objetos não relacionados com a quebra de coco } \\
\text { (coco ou martelo). }\end{array}$ \\
\hline $\begin{array}{l}\text { Percussão de pedra } \\
\text { sobre coco }\end{array}$ & Sujeito golpeia um coco usando uma pedra (martelo) \\
\hline $\begin{array}{l}\text { Quebra eficiente de } \\
\text { coco }\end{array}$ & $\begin{array}{l}\text { Quebra de coco bem-sucedida - Após golpeá-lo, o sujeito tem } \\
\text { acesso ao endosperma. }\end{array}$ \\
\hline Brincadeira social & $\begin{array}{l}\text { Sujeito envolve-se em brincadeira social por mais de } 3 \text { segundos e } \\
\text { pode ficar menos de } 3 \text { segundos sem brincar para outra frequência } \\
\text { não ser computada }\end{array}$ \\
\hline
\end{tabular}

A fim de verificarmos se quem manipula mais objetos e se quem está mais envolvido em quebra de coco, seja por meio de percutir uma pedra no coco ou de quebrar coco com sucesso, é o sujeito que brinca mais, fizemos um teste de correlação não paramétrica, a correlação de Spearman. Para 
compararmos as diferenças entre os dados encontrados em machos e fêmeas em cada grupo de estudo, fizemos o teste não paramétrico de comparação de médias de medidas independentes, Mann-Whitney. Por fim, para compararmos os dados obtidos dos mesmos indivíduos nas duas coletas de dados na Fazenda Boa Vista, utilizamos o teste não paramétrico de comparação de médias de medidas repetidas, Wilcoxon, já que os dados não têm uma distribuição normal. Aplicamos o teste de Spearman comparando as frequências de "manipulação", "percussão de pedra no coco" e "quebra proficiente", com frequências relativas (FR) de "brincadeiras sociais", entre todos os indivíduos, entre todos os machos e fêmeas de cada coleta.

Para realizar as análises estatísticas, utilizamos o programa BioEstat 3.0 (Ayres et al, 2003). 


\section{RESULTADOS}

\section{COLETA DE DADOS}

\subsection{PET:}

No PET obtivemos 121,15h úteis de observação dos indivíduos (Tabela 4), ou seja, o tempo total do focal menos o tempo em que o animal não foi visto foi utilizado.

Os dados foram coletados entre Agosto e Dezembro de 2011, seguindo uma rotina de campo de aproximadamente quatro dias por semana, iniciando o trabalho de campo no período da manhã, por volta das $9 \mathrm{~h}$ até às $16 \mathrm{~h}$, totalizando aproximadamente $170 \mathrm{~h}$ de esforço de campo.

Durante a coleta de dados, sorteios prévios foram feitos a fim de se organizar uma sequência de animais a coletar dados. Quando o animal não era encontrado em 5 minutos, o seguinte da lista era procurado.

Procurei coletar a mesma quantidade de focais para cada animal e procurei fazer focais dos sujeitos sem repeti-los até que todos da lista tivessem sido estudados.

\subsection{BV1:}

Obtivemos 112,52 h úteis de observação dos indivíduos na BV1 (tabela $5)$.

A rotina de campo se iniciava às 7:00 h. Procurávamos os animais, que normalmente estavam próximo ao Esconderijo e assim que os encontrávamos, dávamos cocos, milhos e bananas aos animais. Passávamos 
coletando dados até umas $14 \mathrm{~h}$, hora em que os animais iam para longe do Esconderijo e não conseguíamos acompanhá-los. O esforço de campo total durante o mês de julho foi de aproximadamente $170 \mathrm{~h}$.

Procurávamos fazer focais dos animais de maneira a manter aproximadamente a mesma quantidade de focais coletados para cada um e podíamos coletar novamente o focal do mesmo animal depois de $2 \mathrm{~h}$ passadas da última sessão de coleta.

\subsection{BV 2:}

Obtivemos 116,55 h de tempo útil de dados na BV2 (Tabela 5).

A rotina de campo se iniciava às 6:00h e terminava geralmente no fim da tarde. Procurávamos os animais com ajuda dos guias moradores da região e os seguíamos durante todo o dia. Coletávamos focais de todos os animais antes de coletar novamente dados sobre o comportamento do mesmo animal. O esforço em campo foi de aproximadamente 240h de trabalho. Em BV2 dávamos comidas poucas vezes para atrair os animais, em mais ou menos sete dias de todos os dias de coleta.

A Tabela 4 apresenta o tempo total de coleta de dados no PET:

Tabela 4 - Tempo total de coleta no PET

Tempo total de coleta, em horas, PET. Nome, sexo e faixa etária dos indivíduos.

\begin{tabular}{|l|l|l|l|}
\hline TEMPO TOTAL DE COLETA NO PET \\
\hline Nome & Sexo & Faixa Etária & T (h) \\
\hline Açúcar & Macho & Infante & 6,83 \\
\hline Café & Macho & Infante & 7,32 \\
\hline Buli & Macho & Infante & 6,39 \\
\hline Vegan* & Macho & Infante & 2,97 \\
\hline Didi & Macho & Infante & 4,68 \\
\hline Franja & Macho & Infante & 4,99 \\
\hline
\end{tabular}




\begin{tabular}{|l|l|l|l|}
\hline Morango & Macho & Infante & 5,94 \\
\hline Careca & Macho & Juvenil & 6,21 \\
\hline Vodca & Macho & Juvenil & 7,11 \\
\hline Floyd & Macho & Juvenil & 6,88 \\
\hline Frapê & Macho & Juvenil & 7,28 \\
\hline Caju & Macho & Juvenil & 6,96 \\
\hline Acácio & Macho & Juvenil & 7,26 \\
\hline Gorila & Fêmea & Juvenil & 6,50 \\
\hline Val & Fêmea & Juvenil & 7,11 \\
\hline Flor & Fêmea & Juvenil & 7,18 \\
\hline Cuca & Fêmea & Juvenil & 6,51 \\
\hline Fritz & Fêmea & Juvenil & 6,19 \\
\hline Alice & Fêmea & Juvenil & 6,84 \\
\hline
\end{tabular}

* Sujeito morreu durante o segundo mês de coleta

A Tabela 5 apresenta o tempo total de coleta de dados em BV1 e BV2:

Tabela 5 - Tempo total de coleta em BV1 e BV2

Tempo total de coleta $(T)$, em horas, de dados na BV I e BV II. Nome, sexo e faixa etária dos indivíduos.

\section{TEMPO TOTAL DE COLETA EM BV1 E BV2}

\begin{tabular}{|l|l|l|l|l|}
\hline Nome & Sexo & Faixa Etária & T. BV 1 & T. BV 2 \\
\hline Didi $^{*}$ & Macho & Infante & ---- & 8,89 \\
\hline Presente & Macho & Infante & 6,28 & 10,14 \\
\hline Coco & Macho & Juvenil & 10,88 & 10,55 \\
\hline Pati & Macho & Juvenil & 12,20 & 9,50 \\
\hline Cangaceiro & Macho & Juvenil & 10,23 & 9,47 \\
\hline Catu & Macho & Juvenil & 12,80 & 9,68 \\
\hline Tomate & Macho & Juvenil & 13,04 & 9,90 \\
\hline Chani & Fêmea & Infante & 4,96 & 9,51 \\
\hline Thaís & Fêmea & Infante & 5,57 & 9,94 \\
\hline Paçoca & Fêmea & Juvenil & 12,78 & 9,56 \\
\hline
\end{tabular}




\begin{tabular}{|l|l|l|l|l|}
\hline Pamonha & Fêmea & Juvenil & 12,23 & 10,18 \\
\hline Doree & Fêmea & Juvenil & 11,55 & 9,23 \\
\hline
\end{tabular}

* Sujeito nascido entre a primeira e a segunda coleta

\section{FR DE TODOS OS INDIVÍDUOS}

Apresentamos, a seguir (Tabela 6), os dados de FR dos comportamentos "manipulação", "brincadeira social", "percussão de pedra sobre o coco" e "quebra proficiente", para todos os indivíduos do PET e de BV1 e BV2, separando em subgrupos de machos e fêmeas:

Tabela 6: FR (1/min) dos comportamentos de cada indivíduo durante as coletas PET, BV1 e BV2

\begin{tabular}{|c|c|c|c|c|}
\hline \begin{tabular}{|l} 
FR DOS C \\
E PET
\end{tabular} & UPORTAM & OS DE CA & VDIVÍDUO DURANTE AS & ETAS BV1 \\
\hline PET & Manipulação & $\begin{array}{l}\text { Brincadeira } \\
\text { Social }\end{array}$ & Percussão de pedra no coco & $\begin{array}{l}\text { Quebra } \\
\text { proficiente }\end{array}$ \\
\hline Machos & & & & \\
\hline Acácio & 2,806955313 & 0,238257091 & 0,097258044 & 0,006666667 \\
\hline Caju & 3,149212968 & 0,145759314 & 0,043438788 & 0,013124156 \\
\hline Frapê & 2,920972059 & 0,22011654 & 0,023656876 & 0,002218599 \\
\hline Floyd & 2,956101036 & 0,083300413 & 0,042814679 & 0,00475541 \\
\hline Vodca & 2,63651122 & 0,174609906 & 0 & 0 \\
\hline Careca & 2,144141415 & 0,274739927 & 0 & 0 \\
\hline Buli & 3,030945291 & 0,120360542 & 0 & 0 \\
\hline Morango & 2,975856104 & 0,15591443 & 0 & 0 \\
\hline Franja & 3,158927513 & 0,201229661 & 0 & 0 \\
\hline Didi & 2,563906715 & 0,131243566 & 0 & 0 \\
\hline Café & 2,728421454 & 0,132146983 & 0 & 0 \\
\hline
\end{tabular}




\begin{tabular}{|c|c|c|c|c|}
\hline Açúcar & 2,186336016 & 0,248382785 & 0 & 0 \\
\hline Vegan & 2,244427464 & 0,138852446 & 0 & 0 \\
\hline \multicolumn{5}{|l|}{ Fêmeas } \\
\hline Val & 2,822094847 & 0,11005198 & 0 & 0 \\
\hline Gorila & 3,232361488 & 0,21974786 & 0 & 0 \\
\hline Alice & 3,225239007 & 0,038702185 & 0 & 0 \\
\hline Fritz & 2,302011 & 0,021299636 & 0,053924384 & 0,012812101 \\
\hline Cuca & 2,670263981 & 0,0390909 & 0,148181315 & 0,046004042 \\
\hline Flor & 2,787881781 & 0,07475148 & 0 & 0 \\
\hline BV1 & Manipulação & $\begin{array}{l}\text { Brincadeira } \\
\text { Social }\end{array}$ & $\begin{array}{l}\text { Percussão de pedra sobre } \\
\text { coco }\end{array}$ & $\begin{array}{l}\text { Quebra } \\
\text { proficiente }\end{array}$ \\
\hline \multicolumn{5}{|l|}{ Machos } \\
\hline Presente & 0,270078748 & 0,073312829 & 0,003923618 & 0 \\
\hline \begin{tabular}{|l|} 
Cangaceir \\
0
\end{tabular} & 1,552122505 & 0,09438296 & 0,060872871 & 0,001377422 \\
\hline Catu & 1,360169943 & 0,067898853 & 0,07890133 & 0,010109581 \\
\hline Pati & 1,485143857 & 0,142954066 & 0,02925112 & 0,018458678 \\
\hline Tomate & 1,169775587 & 0,051607527 & 0,035170724 & 0,005247579 \\
\hline Coco & 1,596337481 & 0,087135004 & 0,046119417 & 0 \\
\hline \multicolumn{5}{|l|}{ Fêmeas } \\
\hline Doree & 0,31605411 & 0,02070183 & 0,305101297 & 0,007102001 \\
\hline Paçoca & 0,236263807 & 0,04373861 & 0,210128737 & 0 \\
\hline Pamonha & 0,262470214 & 0,016024737 & 0,348575631 & 0,002381066 \\
\hline Chani & 0,544081528 & 0,031650223 & 0,013578204 & 0 \\
\hline Thaís & 0,322649024 & 0,070669102 & 0 & 0 \\
\hline BV2 & Manipulação & $\begin{array}{l}\text { Brincadeira } \\
\text { Social }\end{array}$ & Percussão de pedra no coco & $\begin{array}{l}\text { Quebra } \\
\text { proficiente }\end{array}$ \\
\hline
\end{tabular}




\begin{tabular}{|c|c|c|c|c|}
\hline \multicolumn{5}{|l|}{ Machos } \\
\hline Didi & 1,674809956 & 0,021444564 & 0 & 0 \\
\hline Presente & 2,135416403 & 0,020315342 & 0 & 0 \\
\hline $\begin{array}{l}\text { Cangaceir } \\
0\end{array}$ & 2,362455831 & 0,076469414 & 0,016380057 & 0,007676531 \\
\hline Catu & 2,154852917 & 0,071738675 & 0 & 0 \\
\hline Pati & 2,457976343 & 0,057680032 & 0,009723502 & 0,001614569 \\
\hline Tomate & 2,65966163 & 0,045736758 & 0 & 0 \\
\hline Coco & 2,92403762 & 0,033409283 & 0 & 0 \\
\hline \multicolumn{5}{|l|}{ Fêmeas } \\
\hline Doree & 2,606614457 & 0,017003681 & 0 & 0 \\
\hline Paçoca & 3,059705588 & 0,03734654 & 0 & 0 \\
\hline Pamonha & 2,418482543 & 0,012100195 & 0 & 0 \\
\hline Chani & 2,584489445 & 0,011801756 & 0 & 0 \\
\hline Thaís & 2,794729865 & 0,071468886 & 0 & 0 \\
\hline
\end{tabular}

\section{CORRELAÇÃO ENTRE AS VARIÁVEIS}

As correlações significativas encontradas foram: correlação positiva entre frequências de "manipulação" e "brincadeira social" de todos os indivíduos de BV1 ( $r s=0,6909 ; p=0,0185$; Figura 1) e correlação negativa entre frequências de "brincadeira social" e "bate pedra no coco" no grupo de fêmeas da BV1 ( $r s=-0,9 ; p=0,0374$; Figura 2). As figuras 1 e 2 são apresentadas a seguir: 


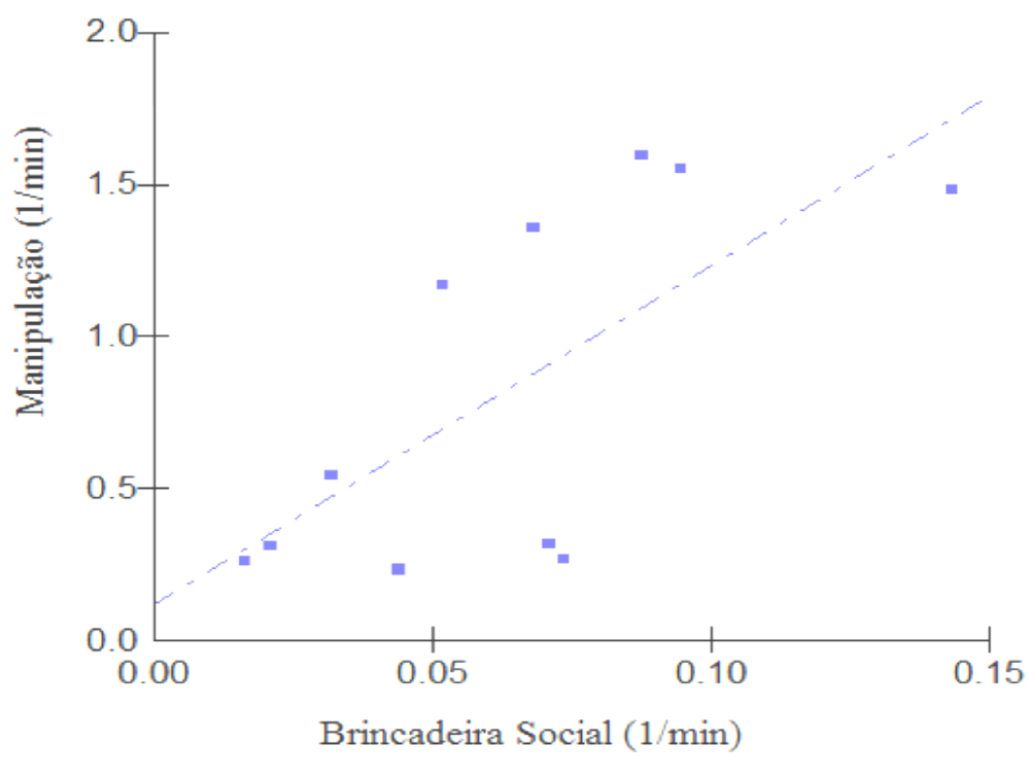

Figura 1. Correlação de Spearman para as variáveis "manipulação" e "brincadeira social" de todos os indivíduos na BV1 ( $r=0,6909 ; p=0,0185)$.

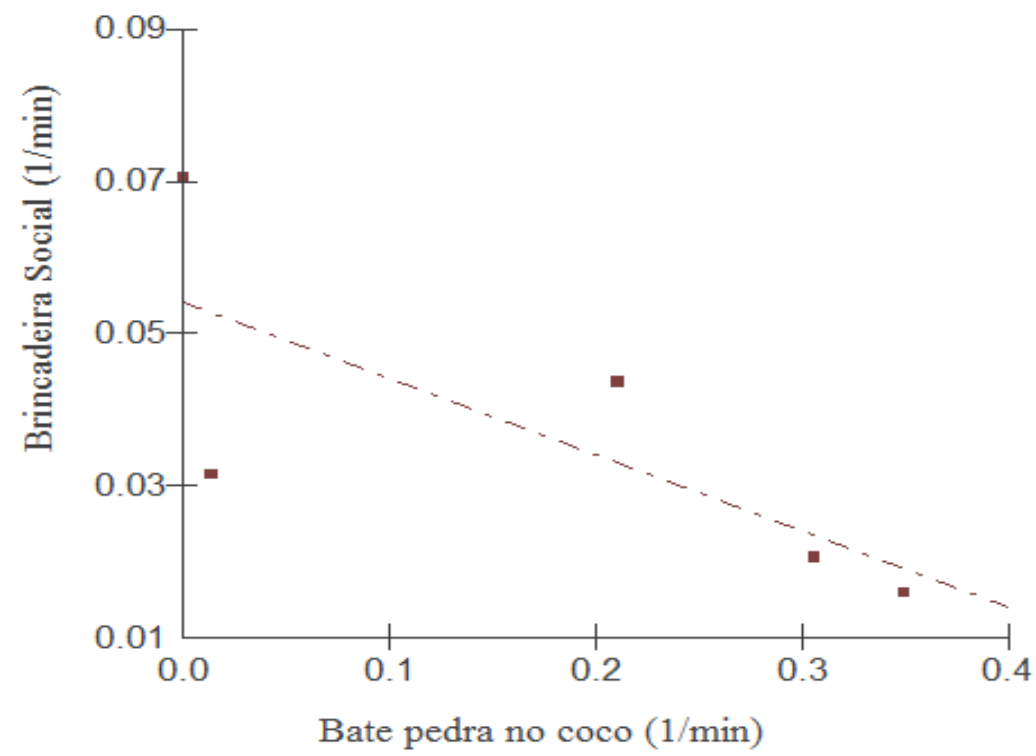

Figura 2. Correlação de Spearman entre as variáveis "brincadeira social" e "percussão de pedra no coco" no grupo de fêmeas na BV1 ( $r s=-0,9 ; p=0,0374)$. 
A seguir estão os testes realizados que testaram possíveis correlações entre as variáveis "Brincadeira Social $x$ Manipulação", "Brincadeira Social $x$ Percussão de pedra no coco" e "Brincadeira Social x Quebra Proficiente". Todas essas correlações foram feitas para: BV1, BV2, PET, incluindo, inicialmente, todos os indivíduos, e depois, separando em grupos contendo apenas machos, apenas fêmeas. De todas essas correlações, apenas duas foram significativas: "Brincadeira social" $x$ "Manipulação" na BV1, e "Brincadeira social" e "percussão de pedra no coco" para fêmeas em BV1 (Tabela 7. No anexo 1 estão todos os resultados das correlações).

Tabela 7: Resultados significativos de testes de correlações não paramétricas

\begin{tabular}{|c|c|c|}
\hline \multicolumn{3}{|c|}{ RESULTADOS SIGNIFICATIVOS DE TESTES DE CORRELAÇÕES NÃO PARAMÉTRICAS } \\
\hline & \multicolumn{2}{|c|}{ Variáveis utilizadas para testar correlação: } \\
\hline Amostra: & \multicolumn{2}{|l|}{ Brincadeira Social x Manipulação } \\
\hline $\begin{array}{l}\text { BV1 (todos os } \\
\text { indivíduos) }\end{array}$ & & Resultados \\
\hline & Coeficiente de Spearman (rs) = & 0,6909 \\
\hline & $t=$ & 2,8671 \\
\hline & $(p)=$ & 0,0185 \\
\hline & Número de pares $=$ & 11 \\
\hline Amostra: & \multicolumn{2}{|c|}{ Brincadeira Social x Percussão de Pedra no coco } \\
\hline \multirow[t]{5}{*}{ BV1 (Fêmeas) } & & Resultados \\
\hline & Coeficiente de Spearman (rs) = & $-0,9$ \\
\hline & $t=$ & $-3,5762$ \\
\hline & $(p)=$ & 0,0374 \\
\hline & Número de pares = & 5 \\
\hline
\end{tabular}




\section{MANIPULAÇÃO E QUEBRA DE COCO}

Em relação às coletas de dados da $B V$, houve maior frequência de manipulação na segunda coleta, na estação chuvosa, tanto para machos $(z=$ $-2,2014 ; p=0,0277)$ quanto para as fêmeas $(z=-2,0226 ; p=0,0431)$. Não consideramos o macho Didi para fazer a análise, já que ele não havia nascido na primeira coleta. A Figura 3 apresenta os resultados:

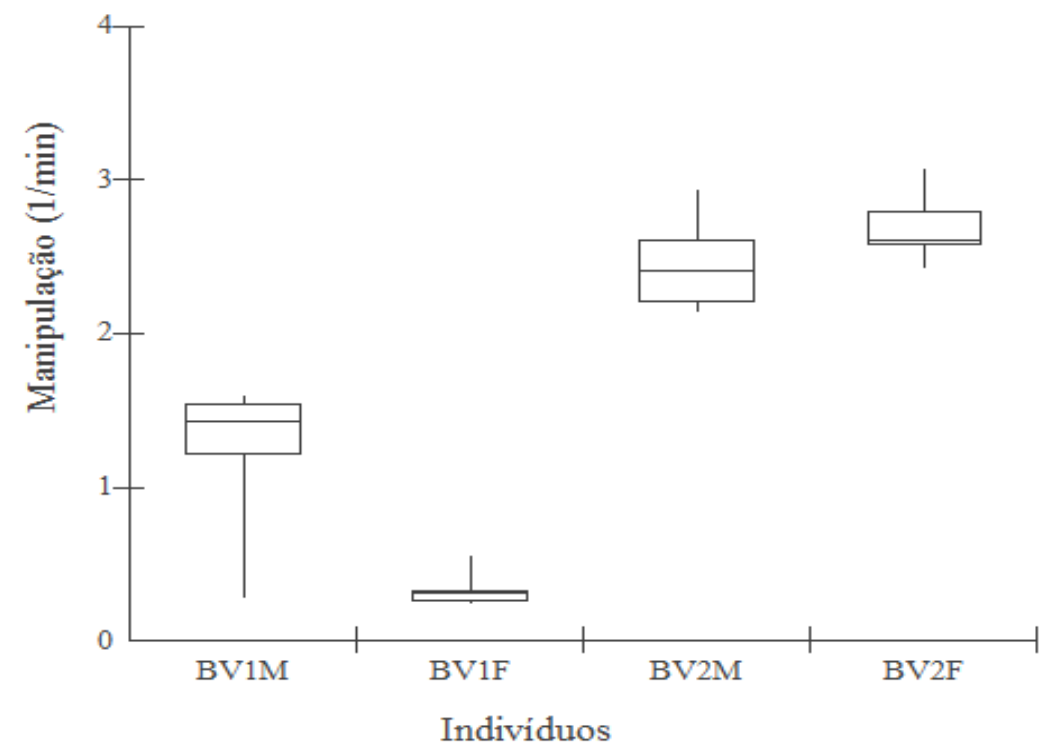

Figura 3. Manipulação: Comparação entre as frequências relativas de BV1 e BV2. Indivíduos machos e fêmeas manipularam mais na BV2: machos $(z=-2,2014$; $p=0,0277)$; fêmeas $(z=-2,0226 ; p=0,0431)$.

Os sujeitos do PET manipularam mais que os sujeitos da BV1. Houve maior frequência de manipulação em machos $(Z(U)=3,4205 ; p=0,0006)$ e em fêmeas $(Z(U)=2,7386 ; p=0,0062)$. Em comparação a $B V 2$, os machos do PET manipularam mais $(Z(U)=2,0207 ; p=0,0433)$ e as fêmeas não apresentaram diferença significativa. 
Não houve diferença significativa entre machos e fêmeas em relação à frequência de manipulação, exceto em BV1, onde os machos manipularam mais que as fêmeas $(Z(U)=2,1909 ; p=0,0285)$.

A Figura 4 apresenta resultados de "manipulação" em BV1, BV2 e PET, para machos e fêmeas:

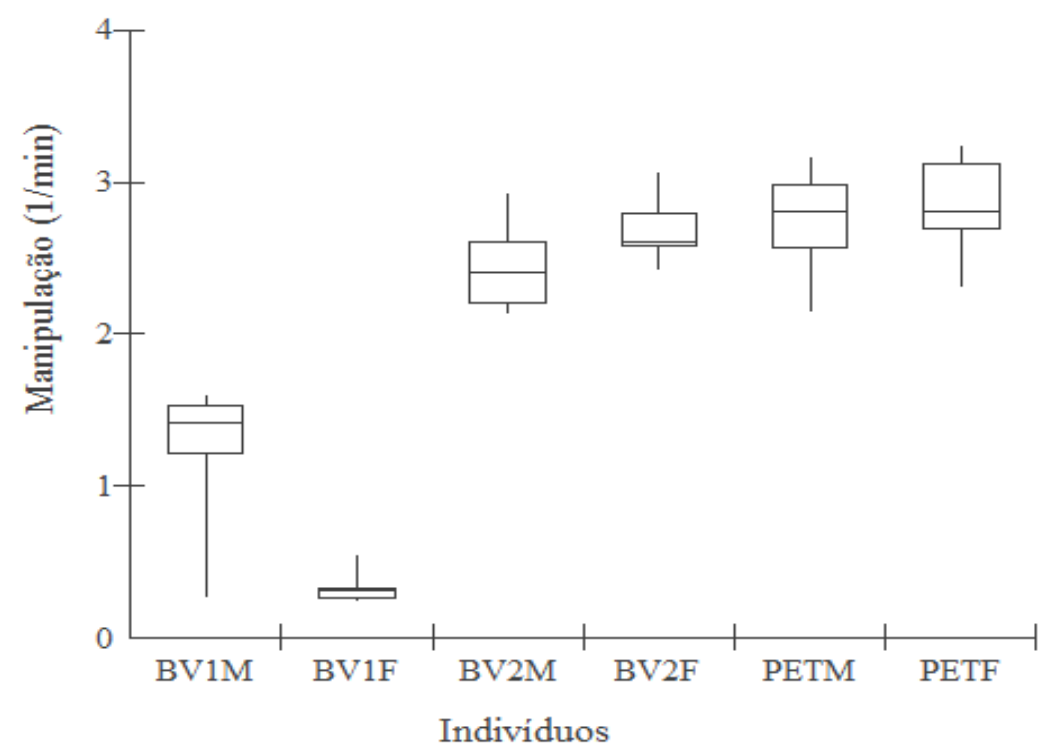

Figura 4. Manipulação em BV1, BV2 e PET. Comparação entre PET e BV1: maior frequência de manipulação em machos $(Z(U)=3,4205 ; p=0,0006)$ e em fêmeas $(Z(U)$ $=2,7386 ; p=0,0062)$ do PET; Comparação entre PET e BV2: os machos do PET manipularam mais $(Z(U)=2,0207 ; p=0,0433)$ e as fêmeas não apresentaram diferença significativa; Comparação entre machos e fêmeas de cada coleta: Machos manipularam mais que fêmeas $(Z(U)=2,1909 ; p=0,0285)$.

Os indivíduos proficientes na quebra de coco na BV1 foram Pati, Catu, Tomate e Cangaceiro, os machos juvenis, e Doree e Pamonha, fêmeas juvenis. Na BV2, somente Pati e Cangaceiro foram vistos quebrando coco. No PET, Acácio, Frapê, Caju e Floyd - machos juvenis, Fritz e Cuca - fêmeas juvenis, foram indivíduos que quebraram coco. Não foram encontradas diferenças significativas. As Figuras 5 e 6 apresentam esses resultados: 


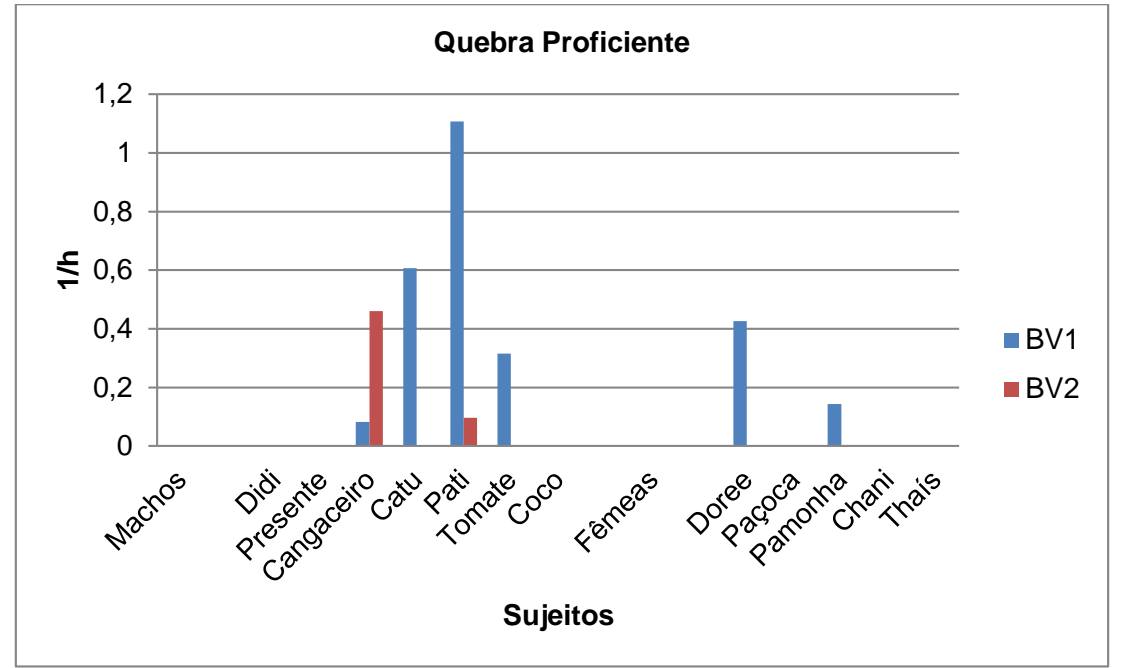

Figura 5. FR de "quebra de coco proficiente" em BV1 e BV2. FR dos indivíduos de BV1, onde foram oferecidos cocos, na estação seca, e de BV2, na estação chuvosa.

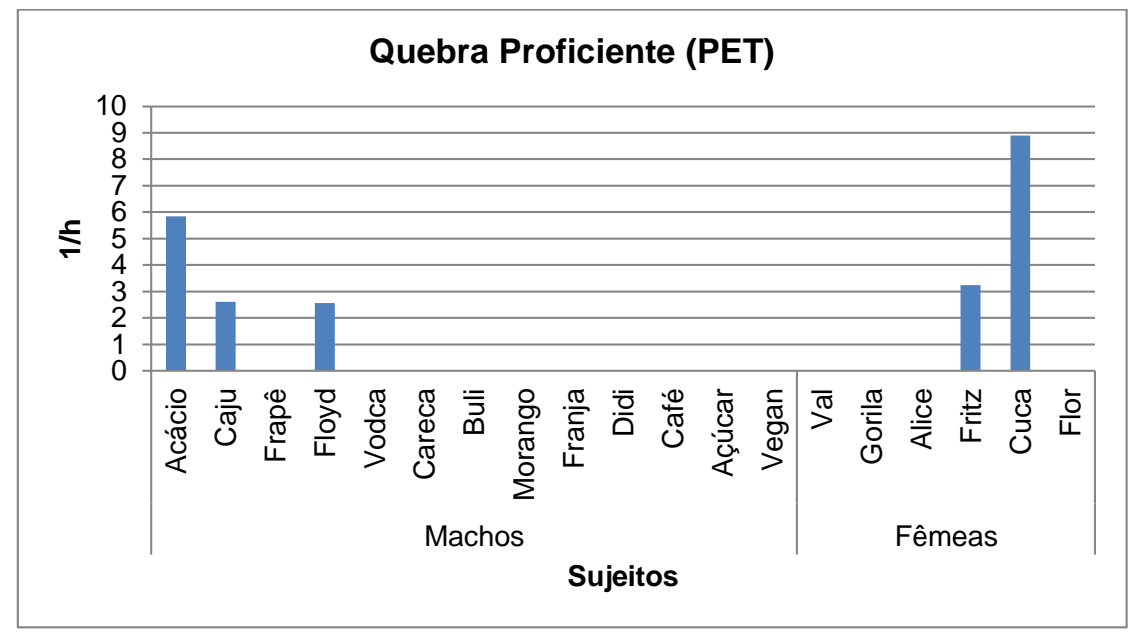

Figura 6. Quebra Proficiente no PET. FR de "Quebra Eficiente", em horas, dos indivíduos do PET.

Em relação ao comportamento "percussão de pedra no coco", os machos da BV1 realizaram tal comportamento em maior frequência $(Z=-$ 2,2014; $p=0,0277$ ) que em BV2; Machos da BV1, quando comparados aos machos do PET $(Z(U)=2,1926 ; p=0,0283)$ também o fizeram mais. Não 
encontramos diferenças significativas na comparação entre machos e fêmeas em nenhuma das coletas. As Figuras 7 e 8 apresentam esses resultados:

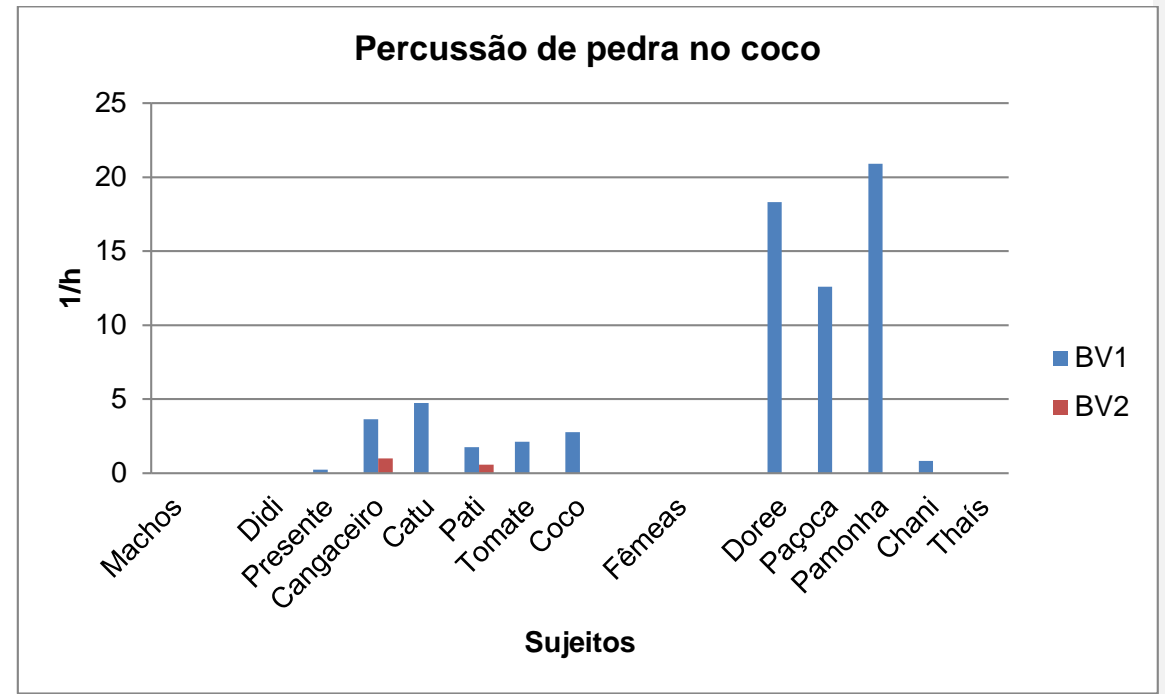

Figura 7. Percussão de coco em BV1 e BV2. FR de "percussão de pedra no coco" dos indivíduos da BV1, onde foi oferecido cocos para eles, na estação seca, e BV2, na estação chuvosa. BV1: Machos apresentaram maior frequência em relação a BV2 ( $z=$ - 2,2014; $p=0,0277)$ e em relação ao PET $(Z(U)=2,1926 ; p=0,0283)$.

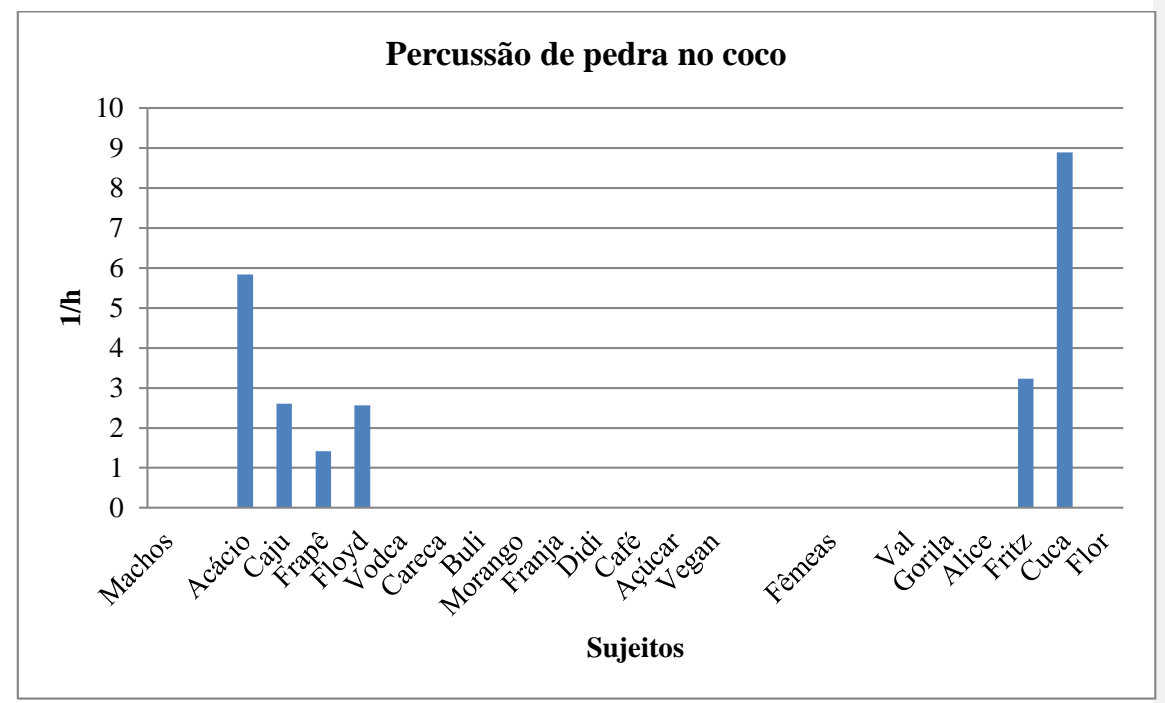

Figura 8. Percussão de pedra no coco no PET. FR de "Percussão de pedra no coco", em horas, dos indivíduos do PET. 


\section{Brincadeira Social}

Os resultados de frequências de envolvimento em "brincadeira social" (Figura 9) indicam algumas diferenças significativas em relação a machos e fêmeas das coletas: Machos brincaram mais na BV1 ( $Z=-1,9917 ; p=0,0464)$; Machos do PET brincaram mais que os machos da BV1 $(Z(U)=2,8066$; $p=0,005)$ e mais que os machos da BV2 $(Z(U)=2,8066 ; p=0,005)$; Fêmeas do PET brincaram mais que as fêmeas da BV2 $(Z(U)=2,0083 ; p=0,0446)$; Machos brincaram mais que as fêmeas na $\operatorname{BV} 1(Z(U)=2,3735 ; p=0,0176)$ e $\operatorname{PET}(Z(U)=2,5435 ; p=0,011)$. Os dados são apresentados a seguir:

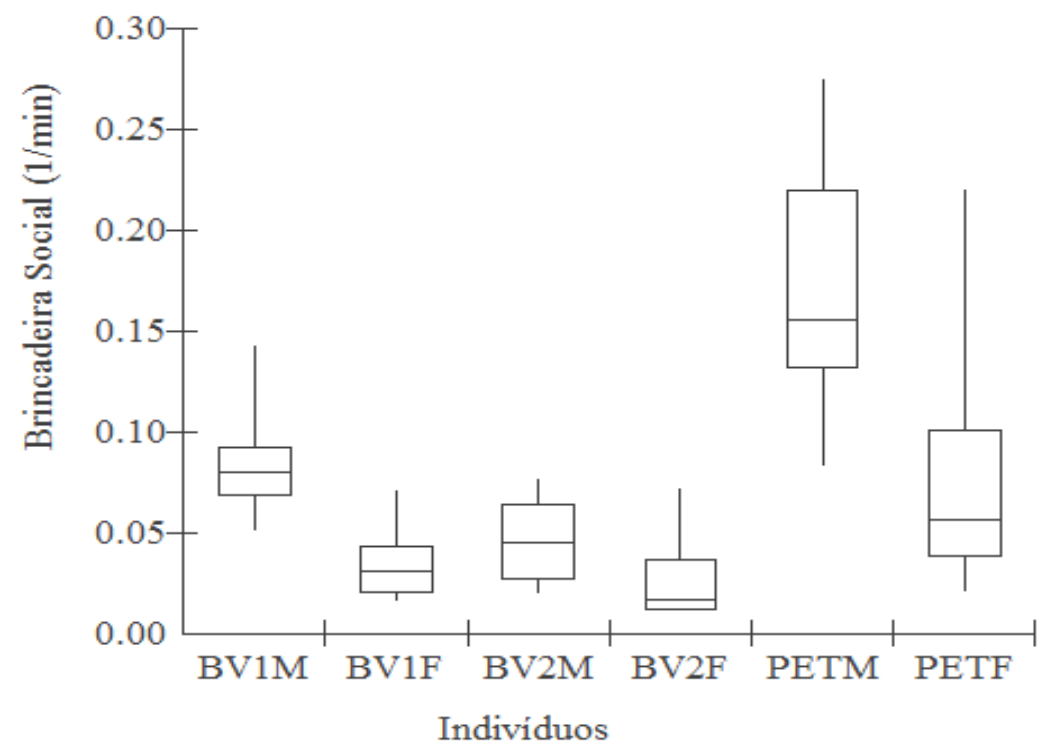

Figura 9. Brincadeira Social em BV1, BV2 e PET. FR de "brincadeira social" na BV1 e BV2 e no PET. Machos brincaram mais na BV1 $(Z=-1,9917 ; p=0,0464)$; Machos do PET brincaram mais que os machos da BV1 $(Z(U)=2,8066 ; p=0,005)$ e mais que os machos da BV2 $(Z(U)=2,8066 ; p=0,005)$; Fêmeas do PET brincaram mais que as fêmeas da BV2 $(Z(U)=2,0083 ; p=0,0446)$; Machos brincaram mais que as fêmeas na $\operatorname{BV} 1(Z(U)=2,3735 ; p=0,0176)$ e PET $(Z(U)=2,5435 ; p=0,011)$.

Os resultados significativos obtidos a partir de testes estatísticos MannWhitney (quando comparamos as médias das FR de grupos distintos) e 
Wilcoxon (quando comparamos as médias das FR do mesmo grupo em fases diferentes) são apresentados de maneira simplificada (somente o valor $p$ ) nas tabelas de 8 a 11. Todos os testes, inclusive os não significativos, são apresentados em anexo (Anexos 2 a 5):

Tabela 8: Resultados das comparações entre FR "Manipulação" entre grupos e no mesmo grupo:

Entre grupos: BV1 x BV2 (Wilcoxon), BV1 x PET (Mann-Whitney) e BV2 x PET (MannWhitney). Machos (M): comparação feita entre apenas machos dos grupos; Fêmeas (F): comparação feita entre apenas fêmeas dos grupos.

Dentro do mesmo grupo: Machos (M) e Fêmeas (F) de BV1.

\section{RESULTADOS DAS COMPARAÇÕES ENTRE FR “MANIPULAÇÃO” ENTRE GRUPOS E NO MESMO GRUPO:}

\begin{tabular}{|l|l|l|}
\hline BV1 $x$ BV2 & $M$ & $F$ \\
\hline BV1 $x$ PET & $\begin{array}{l}\text { BV2 > BV1 } \\
(p)=0,0277\end{array}$ & $\begin{array}{l}\text { BV2 > BV1 } \\
(p)=0,0431\end{array}$ \\
\hline BV2 $x$ PET & $\begin{array}{l}\text { PET }>\text { BV1 } \\
(p)=0,0006\end{array}$ & $\begin{array}{l}\text { PET }>\text { BV1 } \\
(p)=0,0062\end{array}$ \\
\hline BV1 & $\begin{array}{l}\text { BV2 }>\text { PET } \\
(p)=0,0433\end{array}$ & - \\
\hline & $M>F(p)=0,0285$ & \\
\hline
\end{tabular}

${ }^{*} p<0,05$ é significativo

Tabela 9: Resultados das comparações entre FR "Brincadeira Social" entre grupos e no mesmo grupo:

Entre grupos: BV1 x BV2 (Wilcoxon), BV1 x PET (Mann-Whitney) e BV2 x PET (MannWhitney). Machos (M): comparação feita entre apenas machos dos grupos; Fêmeas $(\mathrm{F})$ : comparação feita entre apenas fêmeas dos grupos.

Dentro do mesmo grupo: Machos (M) e Fêmeas (F) de BV1.

RESULTADOS DAS COMPARAÇÕES ENTRE FR "BRINCADEIRA SOCIAL" ENTRE GRUPOS E NO MESMO GRUPO

\begin{tabular}{|l|l|l|}
\hline & $M$ & $F$ \\
\hline BV1 $x$ BV2 & $\begin{array}{l}\text { BV1 > BV2 } \\
(p)=0,0464\end{array}$ & ------- \\
\hline BV1 $x$ PET & $\begin{array}{l}\text { PET > BV1 } \\
(p)=0,005\end{array}$ & -------- \\
\hline BV2 $x$ PET & $\begin{array}{l}\text { PET > BV2 } \\
(p)=0,0003\end{array}$ & $\begin{array}{l}\text { PET > BV2 } \\
(p)=0,0446\end{array}$ \\
\hline
\end{tabular}




\begin{tabular}{|l|l|}
\hline BV1 & $\begin{array}{l}M>F \\
(p)=0,0176\end{array}$ \\
\hline PET & $M>F$ \\
& $(p)=0,011$ \\
\hline
\end{tabular}

${ }^{*} p<0,05$ é significativo

Tabela 10: Resultados das comparações entre FR "Percussão de pedra sobre coco" entre grupos e no mesmo grupo:

Entre grupos: BV1 x BV2 (Wilcoxon) e BV1 x PET (Mann-Whitney). Machos (M): comparação feita entre apenas machos dos grupos; Fêmeas $(F)$ : comparação feita entre apenas fêmeas dos grupos.

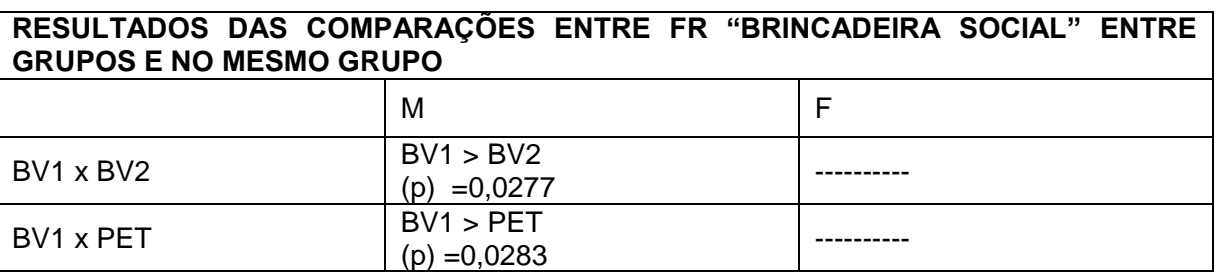

${ }^{*} p<0,05$ é significativo

\section{SÍNTESE DOS RESULTADOS:}

\section{- Correlações:}

A) FR de "Manipulação" e "Brincadeira Social" de todos os indivíduos de BV1 ( $r s=0,6909 ; p=0,0185$ );

B) FR de "Brincadeira Social" e "percussão de pedra no coco" no grupo de fêmeas da BV1 (rs = - 0,9; $p=0,0374$ ).

- Comparação entre médias de FR de comportamentos de machos e fêmeas nas coletas BV1, BV2 e PET: 
A) Manipulação:

Machos: $\mathrm{PET}>\mathrm{BV} 2$ > BV1

Fêmeas: PET e BV2 > BV1

BV1: Machos manipularam mais que fêmeas

B) Brincadeira Social

Machos: $\mathrm{PET}>\mathrm{BV} 2$ > BV1

Fêmeas: PET > BV2

Machos brincaram mais que fêmeas em BV1 e PET

C) Percussão de pedra no coco

Machos: BV1 > PET e BV2

Fêmeas: Sem diferença significativa

Sem diferença significativa entre machos e fêmeas

D) Quebra proficiente

Machos: BV1 > PET e BV2

Fêmeas: Sem diferença significativa em nenhuma das coletas

Sem diferença significativa entre machos e fêmeas 


\section{DISCUSSÃO}

Neste trabalho, partindo da premissa que a brincadeira social é uma forma de explorar o ambiente, nós procuramos verificar se indivíduos que apresentavam maior FR de brincadeira social eram também aqueles mais envolvidos em manipulação de objetos e, consequentemente, mais envolvidos em quebra de cocos. Assim, a motivação para explorar ativaria o comportamento de brincadeira e o comportamento de exploração de objetos. A exploração de objetos traria oportunidades de aprendizagem do comportamento de quebra: de acordo com a perspectiva da Percepção e Ação, os animais poderiam ganhar conhecimento sobre suas potencialidades e as dos objetos, bem como sobre as relações entre os objetos e as ações.

Encontramos correlação entre as variáveis "manipulação", que indica frequências relativas de manipulação de objetos quaisquer, exceto de cocos, e "brincadeira social" de todos os indivíduos na BV1. Inicialmente, a correlação corrobora a hipótese de que há compartilhamento entre motivação para brincar e para explorar. A falta de correlação observada em BV2 e PET não corrobora nossa hipótese, por outro lado.

Os macacos-prego machos manipularam e brincaram mais no PET, em seguida em BV2 e por último em BV1, com diferenças significativas. Não consideramos o macho Didi para fazer a análise, já que ele não havia nascido na primeira coleta e a comparação entre as médias é feita de forma pareada. Houve concordância de decréscimo de taxa de manipulação entre manipulação e brincadeira social concomitantemente, quando estudamos os machos, o que corrobora nossa hipótese de associação entre as variáveis, apesar de não haver resultado significativo no teste de correlação.

Já em relação às fêmeas, manipularam mais no PET e BV2 sem diferença significativa e menos em BV1, com diferença significativa; e brincaram mais no PET do que em BV2, não havendo diferença significativa quando comparadas a BV1. Os resultados são coincidentes, quando observamos a variação de brincadeira social e manipulação, para os machos e parcialmente coincidentes para as fêmeas. Temos que entender o que 
mudou de BV1 para BV2, já que o grupo é o mesmo, e temos que entender as diferenças do grupo do PET e o grupo da BV1/BV2.

É importante salientar que a variável "manipulação" não inclui manipulação de cocos. Essa escolha de procedimento de coleta de dados foi feita visando estudar aspectos de manipulação dos animais que tivesse um caráter de exploração em condições mais próxima do que seria "natural". Quando contabilizamos as frequências relativas de manipulação, foi incluída frequência de manipulação de outros alimentos oferecidos além de coco, como milhos e bananas, porque eles eram dados para atrair os animais e para tentar mantê-los no "Esconderijo" em BV1 e BV2. Em BV2 dávamos comidas poucas vezes para atrair os animais, mais ou menos sete dias de todos os dias de coleta, e no PET também havia provisão de outros alimentos, em maior quantidade, portanto, a "oferta de comida" era uma constante que ocorreu nas três coletas, em maior ou menor grau.

A oferta de cocos aos animais aconteceu somente em BV1, por isso fizemos a contabilidade da frequência à parte. Houve manipulação de cocos e uso de pedras para quebrá-lo nas três coletas, sendo que em BV2 e PET, os animais encontravam cocos não oferecidos por humanos, com baixas frequências de manipulação.

A coleta BV1 foi realizada na estação de seca, em condições de oferta de comida e oferta de cocos, além de os focais terem sido feitos no Esconderijo (Local onde os experimentos de campo são realizados na fazenda Boa Vista), em sua maioria, ou bem próxima a ele. Nestas condições, os animais manipularam mais coco, por ter sido ofertado. Por haver fácil acesso aos alimentos, e em maior abundância, a frequência de brincadeira foi maior em BV1 se compararmos com BV2, o que está de acordo com a literatura, segundo a qual, a disponibilidade de recursos (alimento, parceiros, espaço, tamanho e tipo de recinto caso os animais vivam em cativeiro) é fator que altera a frequência de brincadeiras (Fagen, 1993; Byrne \& Suomi, 1996). Taxas de brincadeiras decaem quando os alimentos são escassos (Lee, 1984; Barrett et al., 1992).

Explicamos as maiores taxas de brincadeira social e de manipulação no PET pelo motivo de haver suprimento farto de comida e de fontes de comida, 
fator que interfere na frequência de brincadeiras e pelo motivo de haver maior número de infantes (ver tabelas 1 e 2), idade em que manipulam mais (Resende e Ottoni, 2008). Além disso, a alta taxa de manipulação em BV2 (padrão semelhante ao do PET - ver Figura 3) se deveu, provavelmente, ao fato de ter havido suprimento de comida, como no PET, e por haver várias fontes de comida, devido à coleta ocorrer em época de chuvas.

A menor taxa de manipulação e brincadeira social foi observada em BV1 porque houve abundância de cocos, e a quebra de coco é uma atividade com motivação extrínseca (o animal supre necessidades energéticas quando o come) e parece ter motivação intrínseca (Barto et al., 2004; Berthier et al., 2005), de acordo com a classificação inicialmente proposta por Berlyne (1960, 1966), no sentido de ser uma atividade, cujas etapas de aprendizagem, como percussão de pedra, por exemplo, poder ser recompensadoras per se (Fragaszy, 1989; Fragaszy et al., 1991; Byrne \& Suomi, 1998). Logo, havendo oferta de coco, os animais se envolvem nela (Spagnoletti, 2009), e deixam de fazer outras atividades, como brincar com co-específicos e manipular outros objetos que não sejam cocos. Outro argumento a favor de supor que a ação seja recompensadora por si só, é que há intercalação entre brincadeira social e quebra de cocos por indivíduos imaturos (Resende, 2004).

Nesse sentido, isso é o que ocorre com a manipulação de pedras realizadas pelos macacos japoneses (Macaca fuscata) estudos por Huffman (1984). Esses animais coletavam pedras, juntavam-nas pilha, espalhavam, seguram uma em cada mão, batiam e esfregavam, carregavam de um lado para outro, sem finalidade aparente e preferencialmente após a alimentação, o que é indicador de ser uma atividade recompensadora por si mesma (Huffman, 1996), assim como aprender a quebrar coco e quebrar coco, que envolvem transporte, seleção, posicionamento e percussão de pedras e cocos.

Quanto às variáveis "percussão de pedra no coco" e "quebra proficiente", para os machos, as frequências em BV1 foram maiores e entre BV2 e PET não houve diferença significativa (BV1 > BV2 e PET), já que houve oferta de cocos em BV1. 
Em BV1, Pati (43-44 meses), Cangaceiro (45-46 meses), Catu (53-54 meses) e Tomate (55-56) quebraram coco. Coco (23,5-24,5 meses) e Presente (3-4 meses), não quebraram e nem percutiram pedra sobre coco. Esses resultados são semelhantes aos de outros trabalhos, em que observaram que jovens obtêm sucesso na quebra a partir de 24 meses (Resende, 2004), em taxas bem menores que os adultos ou ainda, segundo Mannu (2001), não obtêm sucesso antes dos 36 meses.

Em BV2, somente Pati (49-50 meses) e Cangaceiro (51-52 meses) quebraram coco. É importante lembrar que não houve oferta de cocos nessa ocasião, portanto, outros indivíduos não tiveram a oportunidade.

No PET, Acácio (42-47 meses), Caju (34-39), Frapê (31,5-36,5) e Floyd $(30,5-35,5)$ foram sujeitos que quebraram coco de maneira proficiente. Outros dois juvenis, Vodca $(20,5-25,5)$ e Careca (17-22) não quebraram coco, nem realizaram percussão de pedra no coco, o que pode ser explicado pela idade e falta de oferta de cocos.

Quanto às fêmeas e os comportamentos de percussão de pedra no coco e quebra proficiente, não houve diferença significativa entre as coletas, apesar de não termos registrado nenhum desses dois comportamentos em BV2. Em BV1, as fêmeas Pamonha (36 meses) e a gêmea Paçoca, e Doree (44-45) percutiram pedra sobre o coco e Pamonha e Doree quebraram coco. Para a juvenil Paçoca não houve registro de quebra proficiente. As infantes Chani (5-6 meses) e Thaís (8-9 meses) não fizeram percussão de pedra sobre o coco e nem quebraram coco, o que está de acordo com o encontrado por Mannu (2001) e Resende (2004), que observaram proficiência de quebra de coco em seus estudos a partir de 36 e 24 meses respectivamente.

A correlação negativa entre as variáveis "brincadeira social" e "percussão de pedra no coco" no grupo de fêmeas na BV1 indica que as fêmeas brincaram menos de brincadeira social e que percutiram mais pedra em coco, o que pode ser considerada uma atividade lúdica ou exploratória. As fêmeas gêmeas, Pamonha e Paçoca, de 36 meses apresentaram alta taxa de percussão de pedras nos cocos, o que se deveu, provavelmente, à falta de proficiência na atividade, como indicado no gráfico de "quebra proficiente" (Figura 5). A fêmea Pamonha quebrou coco, mas o registro de quebra foi 
pequeno (ver tabela 6). No caso de Doree, que apresenta alta taxa de batidas de pedras nos cocos e de quebra proficiente, podemos supor que ela tenha menos força que os machos, ou seja, ela quebra cocos, mas precisa de mais golpes para romper o endocarpo.

No PET, as fêmeas Cuca (45,5-50,5 meses) e Fritz (52,5-57,5 meses) quebraram coco, e as fêmeas Gorila (20,5-25,5 meses), Val (34-39 meses), Flor (41-46 meses) e Alice (60,5-61,5 meses) não foram vistas realizando essas atividades.

Machos têm maior massa e por isso têm uma demanda enérgica maior que fêmeas, por essa razão, poderiam se envolver mais que elas em atividade de quebra de coco. Macacos-prego ilustram como o uso de ferramentas pode ser impactado por dimorfismo sexual devido ao tamanho do corpo, sendo a diferença de massa e resistência muscular entre os sexos mais marcante em macacos-prego que em humanos e chimpanzés (Fragaszy et al., 2010).

Se considerarmos estudos com chimpanzés (Pan troglodytes) de diferentes populações, as fêmeas usam mais ferramentas que os machos para quebrar cocos (Boesch \& Boesch, 1984). Além disso, fêmeas "pescam" cupins três vezes mais que machos (McGrew, 1979; Pandolfi et al., 2003). Isso indica que, dependendo da espécie, da ferramenta e do contexto ecológico, fêmeas podem usar mais ferramentas do que machos.

Trabalhos anteriores detectaram diferença entre os sexos no comportamento de quebra de coco. Por exemplo, diversos autores apontam que machos exibiram maior atividade de quebra de coco (Mannu \& Ottoni, 2001; Mannu, 2002; Resende, 2004; Ramos-da-Silva, 2008; Coelho, 2009; Spagnoletti et al., 2011), tendo sido também os sujeitos mais observados por co-específicos durante atividade de quebra (Resende, 2004). A percussão de pedras pode ser usada como display de agressividade e como display sexual (Moura, 2007) ou também para atrair a atenção de fêmeas (seria um indicador de aptidão), segundo Boinski (2004). Porém, neste trabalho, não encontramos diferenças significativas em relação às variáveis "percussão de pedra no coco" e "quebra proficiente" quando comparamos machos e fêmeas. $O$ trabalho de Resende (2004) foi também realizado no PET. Uma possível 
explicação para não termos aqui encontrado diferença significativa entre os sexos no PET é a de que a presença de 7 infantes, que não quebram coco, no grupo de machos tenha inflado o tamanho da amostra e a quebra de coco ficou como um comportamento em proporção menor dentro do grupo.

Machos brincaram mais que as fêmeas de brincadeiras sociais na BV1, BV2 e PET, embora a diferença em BV2 não tenha sido significativa. Esse resultado converge com outros na literatura que observaram que machos juvenis tendem a brincar mais que as fêmeas e por períodos mais longos em episódios de brincadeiras turbulentas ou de luta, de ataques de uns aos outros, mordidas, empurrões e de rolar no chão com outros membros do grupo (rough-and-tumble play), geralmente outros machos, sem configurar um comportamento agonístico, enquanto que fêmeas jovens são mais interessadas em filhotes do grupo em certas espécies primatas (Wallen, 2005; Walters, 1987). A preferência de machos juvenis por brincadeiras turbulentas foi também vista em macacos japoneses, Macaca fuscata, (Hayaki, 1983); resos, Macaca mulatta (Lovejoy \& Wallen, 1998), gorilas, Gorilla gorilla (Watts e Pusey, 1993). Esse resultado que encontramos é consoante com o observado em estudos com macacos-prego, Sapajus sp., (Welker et al., 1989; Izar, 1994; Resende e Ottoni, 2002; Resende, 2004; Fragaszy et al, 2004b; Suomi e Paukner, 2008; Verderane, 2010; Winandy, 2012.).

Podemos supor falta de significância entre frequência de brincadeira de machos e fêmeas de machos e fêmeas em BV2 devido a haver menor provisão de alimentos e os macacos passarem mais tempo se locomovendo e forrageando.

Izar (1994) e Winandy (2012) verificaram que jovens fêmeas investiriam mais na construção e manutenção de redes afiliativas, por meio de catação, do que os jovens machos, que passam mais tempo envolvidos na brincadeira social. $O$ fato de termos verificado que os machos deste trabalho também passam mais tempo na brincadeira social do que as fêmeas em BV1 e PET pode indicar que eles estejam investindo nas relações sociais por meio da brincadeira e as fêmeas poderiam estar usando outra estratégia.

Os resultados obtidos não corroboram nossas hipóteses. Não podemos estabelecer um vínculo direto e universal entre brincadeira social e 
manipulação para todos os indivíduos. Encontramos aumento de manipulação e brincadeiras sociais quando houve maior provisão de alimentos, no PET, e em BV1, o que pode indicar que a motivação para manipular e se envolver em brincadeiras sociais seja compartilhada em machos e as fêmeas usariam outras estratégias de exploração do ambiente social. A discussão sobre a motivação para explorar e para brincar ser a mesma, apesar de não corroborada, merece continuidade. Ambos os comportamentos contribuem para o aprendizado sobre características e potencialidades do meio ambiente, tanto do meio não social quanto do social.

Segundo von Hofsten (2009), existe uma importante diferença entre ações voltadas para o mundo social e ações voltadas para o mundo físico. $O$ fato de uma ação de um membro ser voltada para outro membro do grupo cria uma situação mais dinâmica e complexa do que ações dirigidas a objetos físicos, cujas respostas são mais previsíveis. Na vida em grupo, movimentos específicos, gestos, sons ou expressões faciais (Darwin, 1872; Ekman, 1993) transmitem informações sobre estado emocional, intenções e direção da atenção de quem os exibem, quando se trata de humanos. É esperado que o desenvolvimento do entendimento de crianças a respeito de outras pessoas seja paralelo ao desenvolvimento de suas próprias ações. O autor argumenta que como infantes se tornam mais proficientes no domínio de agir, eles rapidamente desenvolvem habilidades sociais que requerem o conhecimento das ações de outros indivíduos.

Explorar é atividade realizada por quase todos os animais e brincadeiras, não (Pisula, 2008). Esses fatos não descartam a possibilidade de o aparecimento de comportamentos lúdicos ter ocorrido a partir de mecanismos neuronais de exploração e que possam compartilhar a mesma motivação. As bases neurológicas relacionadas com a expressão do comportamento lúdico e exploratório, citadas anteriormente, não se convergem a princípio e ambos os comportamentos têm origem filogenética distintas, sendo o comportamento lúdico mais recente (Pisula, 2008). Panksepp (2011) indica a necessidade de mais estudos de regiões cerebrais ativadas enquanto um mamífero brinca. 
Fragaszy (2012) discute sobre a Teoria da Construção de Nicho (OdlingSmee et al., 2003), que sustenta que organismos são participantes ativos em sua própria evolução. Por meio de suas ações e escolhas, modificam seus próprios habitats e recursos do ambiente, bem como o nicho de outras espécies no imediato momento em que agem e fazem escolhas, ou seja, ele constrói seu nicho. Nesse sentido, um organismo modifica as pressões seletivas que atuam sobre si mesmo, sobre outros indivíduos de sua espécie e sobre indivíduos de outras espécies, e essas modificações podem perdurar gerações (Laland \& O'Brien, 2012). Desta forma, explorar o ambiente, seja manipulando ou brincando, é um meio de o organismo ser agente ativo no processo evolutivo, e a investigação da motivação desse processo é um desafio. 


\section{CONCLUSÕES}

Verificamos que os machos juvenis apresentaram relação diretamente proporcional entre manipulação e brincadeiras sociais, o que pode indicar que exploram o ambiente social por meio de brincadeiras sociais e as fêmeas utilizam outras estratégias. Corroborando a literatura, a brincadeira social é mais recorrente em machos imaturos, que participaram mais que as fêmeas das brincadeiras sociais quando havia grande provisionamento de alimentos no ambiente selvagem e no semilivre. Não houve vínculo entre altas taxas de brincadeiras sociais e maior envolvimento em quebra de coco, assim como não houve um vínculo direto entre exploração por meio de manipulação e brincadeiras sociais. Determinar por meio da observação do comportamento se há uma motivação compartilhada entre brincar e manipular, considerando que são ações relacionadas à exploração, não é tarefa fácil e assim nossos resultados não nos permitem obter uma conclusão enfática, mas indicam um caminho a ser percorrido, que pode passar por uma depuração das categorias comportamentais usadas, e inclusão de novos temas de pesquisa que abarquem, por exemplo, o estudo de cada indivíduo e suas idiossincrasias. 


\section{REFERÊNCIAS}

ALTMANN, J. (1974). Observational study of behaviour: sampling methods. Behaviour, 49: 223-265.

AYRES, M.; AYRES JR, M.; AYRES, D.L.; SANTOS, A.A.S. (2003). BioEstat 3.0: aplicações estatísticas nas áreas das ciências biológicas e médicas. Sociedade Civil Mamirauá, CNPq, Belém. 290pp.

BALDWIN, J. D. \& BALDWIN, J. I. (1997).Behavioral principles in everyday life.Upper Saddle River, NJ: Prentice Hall.

BARRETT, LOUISE, ROBIN I. M. DUNBAR, AND PATSY DUNBAR. (1992). Environmental influences on play behaviour in immature gelada baboons. Animal Behaviour 44:111-15.

BARTO, A. G., SINGH, S. \& CHENTANEZ, N. (2004). Intrinsically motivated learning of hierarchical collections of skills. In Proceedings of the International Conference on Developmental Learning (ICDL), 2004.

BARTON, R. A. (2012). Embodied cognitive evolution and the cerebellum.Philosophical Transactions of the Royal Society B: Biological Sciences,367(1599), 2097-2107.

BATES, E. (1979). The biology of symbols: some concluding thoughts. In "The Emergence of Symbols: Cognition and Communication in Infancy", eds. E. Bates, L. Benigni, I. Bretherton, L. Camaioni \& V. Volterra. New York (NY): Academic Press, 315-70.

BECKOFF, M., \& ALLEN, C. (1998). Intentional communication and social play: How and why animals negotiate and agree to play. In M. Beckoff \& J. 
Byers (Orgs.), Animal play: Evolutionary, comparative, and ecological perspectives (pp. 97-114). Cambridge: Cambridge University Press.

BECKOFF, M., \& BYERS, J. (1998). Animal play: Evolutionary, comparative, and ecological perspectives. Cambridge: Cambridge University Press.

BELLEBAUM, C., DAUM, I. (2011). Mechanisms of cerebellar involvement in associative learning. Cortex, 47:128-36.

BERLYNE, D. E. (1960). Conflict, Arousal. and Curiosity. McGraw-Hill, N.Y.

BERLYNE, D.E. (1966). Curiosity and exploration. Science 153: 25-33.

BERTHIER, N.; ROSENSTEIN, M.; AND BARTO, A. (2005). Approximate optimal control as a model for motor learning. Psychological Review 112.

BIBEN, M. (1989). Effects of social environment on play in squirrel monkeys (Samiri sciureus): resolving Harlequin's dilemma. Ethology, 81:72-82.

BIBEN, M. (1998). Squirrel monkey play fighting: making the case for a cognitive training function for play. Em M. Beckoff \& J. Byers (Orgs.), Animal Play: Evolutionary, Comparative, and Ecological Perspectives. Cambridge: Cambridge University Press.

BIRKE, L. \& ARCHER, J. (1983). Exploration in animals and humans. England: Van Nostrand Reinhold.

BRIL, B.; DIETRICH, G.; FOUCART, J.; FUWA, K.; HIRATA, S. (2009). Tool use as a way to assess cognition: how do captive chimpanzees handle the weight of the hammer when cracking a nut? Anim Cogn 12:217-235. 
BOESCH, C. \& BOESCH, H. (1983). Optimization of nut-cracking with natural hammers by wild chimpanzees. Behavior, 83, 265-285.

BOESCH, C. AND BOESCH, H. (1984). Possible causes of sex differences in the use of natural hammers by wild chimpanzees. Journal of Human Evolution 13: 415-440.

BOINSKI, S. (2004). The beats of different drummers: percussion as sexual signaling among brown capuchins at Raleighvallen, Suriname. Folia Primatol. $75,238$.

BROSNAN, S. F. (2006). Nonhuman species' reactions to inequity and their implications for fairness. Soc. Justice Res.

BROWNLEE, A. (1954). Play in domestic cattle: an analysis of its nature. Brit. Vet. J. 110:48-68.

BURGHARDT, G. M., WARD, B. AND ROSSCOE, R. (1996). Problem of reptile play: Environmental enrichment and play behavior in a captive Nile softshelled turtle, Trionyx triunguis. Zoo Biol., 15: 223-238.

BURGHART, G. M. (1998). The evolutionary origins of play revisted: Lessons from turtles. In M. Beckoff \& J. Byers (Orgs.), Animal play: Evolutionary, comparative, and ecological perspectives (pp. 1-26). Cambridge:

BYERS J. A., WALKER C. (1995). Refining the motor training hypothesis of play. Am Nat. 146:25-40.

BYRNE, G., SUOMI, S. J (1996). Individual differences in object manipulation in a colony of tufted capuchins. J Hum Evol.31:259-267. 
BYRNE, G., SUOMI, S. J. (1998). Relationship of early infant state measures to behavior over the first year of life in the tufted capuchin monkey (Cebus apella). American Journal of Primatology;44:43-56.

CARLSON, N. R. (2002). Fisiologia do Comportamento. Sétima Edição. Editora Manole.

CARO, T.M. (1988). Adaptive significance of play: are we getting closer? Trends in Ecology and Evolution 3: 50-54.

COELHO, C. G. (2009). Observação por co-específicos e influências sociais na Aprendizagem do uso de ferramentas para quebrar cocos por macacosprego (Cebus sp.) em semiliberdade. Dissertação de mestrado apresentada no Instituto de Psicologia da Universidade de São Paulo.

CRepani, E., MedeiRos, J. S., PALmeirA, A. F., SilVA, E. F. (2008). Relatório do Banco de Dados Geográficos de parte do Núcleo de Desertificação de Gilbués (Municípios de Gilbués e Monte Alegre do Piauí). São José dos Campos: INPE. 254 p. (INPE-15186-RPQ/814).

DARWIN, C. (1872). The expression of the emotions in man and animals, London: John Murray.

DE WAAL, F. (1999). The end of nature versus nurture. Scientific American, December. 94-99.

DUNBAR R. I. M., SHULTZ S. (2007). Evolution in the social brain. Science $317,1344-1347$.

EKMAN, P. (1993). Facial expression and emotion. American Psychologist, 48(4), 384. 
FAGEN, R. (1981). Animal play behaviour. Oxford University Press; New York.

FAGEN R. (1993). Primate juveniles and primate play. In: Pereira ME, Fairbanks LA, editors. Juvenile primates: life history, development, and behavior. Oxford University Press; pp. 182-196. New York.

FAIRBANKS, L. A. (1993). Juvenile Vervet Monkeys: Establishing Relationships and Practicing Skills for the Future. In Juvenile Primates: Life History, Development, and Behavior, M. E. Pereira and L. A. Fairbanks, eds. Pp. 211-227. New York: Oxford University Press.

FERREIRA, R. G.; RESENDE, B. D.; MANNU, M.; OTTONI, E. B ; IZAR, P. (2002). Bird Predation and prey-transference in brown capuchin monkeys (Cebus apella). Neotropical Primates, Washington, v. 10, n. 2, p. 84-89.

FLEAGLE, J. G. (1999). Primate Adaptation and Evolution. San Diego, California: Elsevier Academic Press.

FRAGASZY, D. M. (1986). Time budgets and foraging behaviour in wedgecapped capuchins (Cebus olivaceus): age and sex differences. In: Current Perspectives in Primate Social Dynamics (Ed. by D. M. Taub \& F. A. King), pp. 159e174. New York: Van Nostrand Reinhold.

FRAGASZY, D. M. (1989). Activity states and motor activity in an infant capuchin monkey (Cebus apella) from birth through eleven weeks. Dev Psychobiol. 22:141-157

FRAGASZY D. M.; BAER, J.; ADAMS-CURTIS, L. (1991). Behavioral development and maternal care in tufted capuchins (Cebus apella) and squirrel monkeys (Saimiri sciureus) from birth through seven months. Develop Psychobiol 24(6):375-93. 
FRAGASZY, D. M. \& ADAMS-CURTIS, L. E. (1991). Generative aspects of manipulation in tufted capuchin monkeys (Cebus apella). Journal of Comparative Psychology, 105(4), 387-397.

FRAGASZY, D. M. \& ADAMS-CURTIS, L. E. (1997). Developmental changes in manipulation in tufted capuchins (Cebus apella) from birth through 2 years and their relation to foraging and weaning. Journal of Comparative Psychology, 111(2), 201-211.

FRAGASZY, D., IZAR, P, VISALBERGHI, E., OTTONI, E., GOMES DE OLIVEIRA, M. (2004a). Wild capuchin monkeys (Cebus libidinousus) use anvils and stone pounding tools. American Journal of Primatology 64:359366.

FRAGASZY D. M., VISALBERGHI, E., FEDIGAN, L.M. (2004b). The complete capuchin. Cambridge University Press; Cambridge.

FRAGASZY, D. M.; GREENBERG, R.; VISALBERGHI, E.; OTTONI, E. B.; IZAR. P \& LIU, Q. (2010). How wild bearded capuchin monkeys select stones and nuts to minimize the number of strikes per nut cracked. Animal Behaviour 80: $205-214$

FRAGASZY, D. M. (2012). Community resources for learning: how capuchin monkeys construct technical traditions. Biological Theory, 6(3), 231-240.

FRAGASZY, D. M.; LIU, Q.; WRIGHT, B. W.; ALLEN, A.; BROWN, C. W. (2013). Wild Bearded Capuchin Monkeys (Sapajus libidinosus) Strategically Place Nuts in a Stable Position during Nut-Cracking. PLoS ONE 8(2): e56182. doi:10.1371/journal.pone.0056182

FRECKLeton R. P., HARVEY P. H., PAGEL M. (2002). Phylogenetic analysis and comparative data: a test and review of evidence. Am. Nat. 160, 712-726. 
FREESE, C. H.; OPPENHEIMER, J. R. (1981). The capuchin monkeys, genus Cebus. Ecology and behavior of neotropical primates, v. 1, p. 331-390.

GABBARD, C. (2008). Lifelong Motor Development (5th ed.). San Francisco, CA: Benjamin Cummings, 2008.

GIBSON, E. (1967). Principals of perceptual learning and development. New York: Appleton Century Crofts.

GIBSON, E. J. (1988). Exploratory behavior in the development of perceiving, acting, and the acquiring of knowledge. Annual Review of Psychology, 39, 141.

GIBSON, E. J. (2001). Perceiving the affordances: a portrait of two psychologists. Erlbaum: Mahwah, NJ.

GIBSON, E., \& PICK, A (2000). An ecological approach to perceptual learning and development. Oxford: Oxford University Press.

GIBSON, J. (1979). An ecological approach to perception. Houghton Mifflin: Boston.

GOTTLIEB, G. (2000). Nature and nurture theories. In A. Kazdin (Ed.), Encyclopedia of Psychology. Washington, DC, \& New York: American Psychological Association and Oxford University Press, 2000.

GUMERT, M.D., KLUCK, M., MALAIVIJITNOND, S. (2009). The physical characteristics and usage patterns of stone axe and pounding hammers used by long-tailed macaques in the Andaman Sea region of Thailand. Am. J. Primatol. 71, 594e608. 
HABAS, C. (2010). Functional imaging of the deep cerebellar nuclei: a review. Cerebellum 9, 22-28.

HALL, S. (1998). Object play by adult animals. In M. Beckoff \& J. Byers (Orgs.), Animal play: Evolutionary, comparative, and ecological perspectives (pp. 45-58). Cambridge: Cambridge University Press.

HAYAKI, H. (1983). The social interactions of juvenile Japanese monkeys on Koshima Islet. Primates 24(2): 39-153.

HUFFMAN, M. A. (1984). Stone-play of Macaca fuscata in Arashiyama B troop: transmission of a non-adaptive behavior. Journal of Human Evolution, 13, 725-735.

HUFFMAN, M. A. (1996). Acquisition of innovative cultural behaviors in nonhuman primates: a case study of stone handling, a socially transmitted behavior in Japanese monkeys. Em C. M. Heyes \& B. G. Galef (Orgs.), Social Learning in animals: the roots of culture. San Diego: Academic Press.

HUTT, C. (1966) Exploration and play in children, Symposium of Zoological. Society of London, vol. 18, 61-81.

IZAR, P. (1994). Análise da estrutura social de um grupo de macacos-prego (Cebus apella) em semi-cativeiro. Dissertação de mestrado apresentada no Instituto de Psicologia da Universidade de São Paulo.

IZAR, P. (2004). Female social relationships of Cebus apella nigritus in southeastern Atlantic Forest: an analysis through ecological models of primate social evolution. Behaviour,141:71-99.

Janson \& van Schaik, 1993. 
JABLONKA, E. \& LAMB, M. (2005). Evolution in Four Dimensions - Genetic, Epigenetic, Behavioral, and Symbolic Variation in the History of Life. MIT Press.

JOFFE, T. H. (1997). Social pressures have selected for an extended juvenile period in primates. Journal of Human Evolution, 32: 593-605.

KELTNER, D., HORBERG, E. J., \& OVEIS, C. (2006). Emotions as moral intuitions. In J. P. Forgas (Ed.), Affect in social thinking and behavior (pp. 161175). New York: Psychology Press.

LEGGIO M.G., CHIRICOZZI F.R., CLAUSI S. TEDESCO A.M., MOLINARI M. (2011). The neuropsychological profile of cerebellar damage: the sequencing hypothesis. Cortex, 47, 137-144, IF:7.251.

LEINER H. C. (2010). Solving the mystery of the human cerebellum. Neuropsychology. Rev.20, 229-235.

LERNER, R. (2002). Concepts and theories of human development. (3rd ed). Erlbaum: Mahwah, NJ.

LEWIS, K. P (2000). A comparative study of primate play behaviour: implications for the study of cognition. Folia primatologica, 71, 417-421.

LOCKMAN, J. (2000). A perception-action perspective on tool use development. Child Development, 71(1), 137-144.

LOCKMAN, J. (2006). Tool use from a Perception-action perspective: Developmental and evolutionary considerations. In V. Roux, \& B. Bril (Orgs.), Stone Knapping: the necessary conditions for a uniquely hominin behavior (pp. 319-330). Aberystwyth: McDonald Institute Monographs. 
LOCKMAN, J., \& THELEN, E (1993). Developmental Biodynamics: Brain, Body, Behavior Connections. Child Development, 64, 953-959.

LUI J. H., HANSEN D. V., KRIEGSTEIN A. R. (2011). Development and evolution of the human neocortex. Cell 146, 18-36.

LYNCH, J.W. \& RíMOLI, J. (2000). Demography and social structure of group of Cebus paella nigritus (Goldfuss, 1809, Primates/Cebidae) at Estação Biológica de Caratinga, Minas Gerais. Neotropical Primates, 8: 44-49.

LIU, Q., FRAGASZY, D. M., WRIGHT, B., WRIGHT, K., IZAR, P. \& VISALBERGHI, E. (2011). Wild bearded capuchin monkeys (Cebus libidinosus) place nuts in anvils selectively. Animal Behaviour, 81, 297e305.

LIU, Q., SIMPSON, K., IZAR, P., OTTONI, E., VISALBERGHI, E. \& FRAGASZY, D. M. (2009). Kinematics and energetics of nut-cracking in wild capuchin monkeys (Cebus libidinosus) in Piauí, Brazil. American Journal of Physical Anthropology, 138, 210e220.

LOVEJOY, J.; WALLEN, K. (1988). Sexually dimorphic behavior in grouphoused rhesus monkeys (Macaca mulatta) at 1 year of age. Psychobiology;16:348-356.

LYNCH ALFARO, J. W.; BOUBLI, J. P.; OLSON, L. E.; DI FIORE, A.; WILSON, B.; GUTIÉRREZ-ESPELETA, G. A.; CHIOU, K. L.; SCHULTE, M.; NEITZEL, S.; ROSS, V.; SCHWOCHOW, D.; NGUYEN, M. T.; FARIAS, I.; JANSON, C. H. \& ALFARO, M. E. (2011). Explosive Pleistocene range expansion leads to widespread Amazonian sympatry between robust and gracile capuchin monkeys. Journal of Biogeography. doi: 10.1111/j.13652699.2011.02609.x] 
LYNCH ALFARO, J.W.; SILVA, J.S. \& RYLANDS, A.B. (2012). How Different Are Robust and Gracile Capuchin Monkeys? An Argument for the Use of Sapajus and Cebus. American Journal of Primatology: 1-14.

MANNU, M. \& OTTONI, E.B. (2001). Semi free-ranging tufted capuchins (Cebus apella) spontaneously use tools to crack open nuts. Int. J. Primatol. 22, 347e358.

MANNU, M. (2002). Uso espontâneo de ferramentas por macacos-prego em condições de semi-liberdade: descrição e demografia. Dissertação de mestrado apresentada no Instituto de Psicologia da Universidade de São Paulo.

MANNU, M. \& OTTONI, E.B. (2009). The enhanced tool-kit of two groups of wild bearded capuchin monkeys in the caatinga: tool making, associative use, and secondary tools. American Journal of Primatology 71, 242-251.

MARTIN, P., \& CARO, T. M. (1985). On the functions of play and its role in behavioral development. Advances in the Study of Behavior, 15, 59-103.

MATHER J.A., ANDERSON R.C. (1999). Exploration, Play and Habituation. Journal of Comparative Physiology 113: 333-338.

MOURA, A. C. \& E LEE, P. C. (2004). Capuchin stone tool use in Caatinga dry forest. Science 306:1909.

MOURA, A. (2007). Stone banging by wild capuchin monkeys: an unusual auditory display. Folia Primatol. 78, 36e45.

MCGREW, W.C., (1979). Evolutionary implications of sex differences in chimpanzee predation and tool use. In: Hamburg, D.A., McCown, E. (Eds.), The Great Apes. Benjamin/Cummings, Menlo Park, pp. 441e463. 
NAPIER, J.; P. NAPIER. (1967). A Handbook of Living Primates. London: Academic Press.

ODLING-SMEE, F. J.; LALAND, K. N.; FELDMAN, M. W. (2003). Niche construction: the neglected process in evolution. Princeton University Press, Princeton

OTTONI, E.B., RESENDE, B.D. \& IZAR, P. (2005). Watching the best nutcrackers - what capuchin monkeys (Cebus apella) know about others' tool using skills. Animal Cognition 8(4), 215-21.

OTTONI, E. B. \& IZAR, P. (2008). Capuchin monkey tool use: overview and implications. Evolutionary Anthropology, 17: 171-178.

PANDOLFI, S.S., VAN SCHAIK, C.P., PUSEY, A.E., (2003). Sex differences in termite fishing among Gombe chimpanzees. In: deWaal, F.B.M., Tyack, P.L. (Eds.), Animal Social Complexity: Intelligence, Culture and Individualized Societies. Harvard University Press, Cambridge, pp. 414e418.

PANKSEPP, J. (2002). The MacLean legacy and some modern trends in emotion research. In: Cory Jr., G.A., Gardner Jr., R. (Eds.), The Evolutionary Neuroethology of Paul MacLean. Praeger, Westport, CT, pp. ix-xxvii.

PANKSEPP, J. (2008). The affective brain and core-consciousness: how does neural activity generate emotional feelings? In: Lewis, M., Haviland, J.M., Barrett, L.F. (Eds.), Handbook of Emotions. Guilford, New York, pp. 47-67.

PANKSEPP, J., (1998). Affective Neuroscience: The Foundations of Human and Animal Emotions. Oxford University Press, New York.

PANKSEPP, J., HARRO, J., (2004). The future of neuropeptides in biological psychiatry and emotional psychopharmacology: goals and strategies. In: 
Panksepp, J. (Ed.), Textbook of Biological Psychiatry. Wiley, Hoboken, NJ, pp. 627-660.

PANKSEPP, J. (2011). The basic emotional circuits of mammalian brains: Do animals have affective lives? Neuroscience and Biobehavioral Reviews 35, 1791-1804.

PECIÑA, S. (2008). Opioid reward 'liking' and 'wanting' in the nucleus accumbens. Physiology \& Behavior, 94, 675-680.

PELLIS, S. M. \& PELLIS V. C. (2007). Rough and tumble play and the development of the social brain. Current Directions in Psychological Science, 16: 95-98.

PELLIS, S. M., PELLIS, V. C. \& BELL, H. C. (2010) The Function of Play in the Development of the Social Brain. American Journal of Play. 2(3), 278-298.

PEREIRA, M. E. \& J. ALTMANN. (1985). Development of Social Behavior in Free-Living Nonhuman Primates. In Nonhuman Primate Models for Human Growth and Development, E. S. Watts, ed. Pp. 217-309. New York: Liss.

PISULA, W. (2008). Play and Exploration in Animals-A Comparative Analysis. Polish Psychological Bulletin. Volume 39, Issue 2, Pages 104-107, ISSN (Print) 0079-2993,DOI: 10.2478/v10059-008-0009-4

SUOMI, S. J. \& PAUKNER, A. (2008). Sex differences in play behavior in juvenile tufted capuchin monkeys (Cebus apella). Primates, v. 49, n. 4, p. 288291.

POIRIER, F. E., \& SMITH, E. O. (1974). Socializing functions of primate play.American Zoologist, 14(1), 275-287. 
RAMNANI N., MIALL C. R. (2004). A system in the human brain for predicting the actions of others. Nat. Neuroscience. 7, 85.

RAMOS DA SILVA, E.D., 2008. Escolha de alvos coespecificos na observação do uso de ferramenta por macaco-prego (Cebus libidinosus) selvagens. Tese de Mestrado em Psicologia Experimental, Universidade de São Paulo

REEDER, D. M. \& WILSON, D. E. (EDS) (2005). Mammal species of the world: a taxonomic and geographic reference. Third edition. The Johns Hopkins University Press, Baltimore.

RASA, O. A. E. (1984). A motivational analysis of object play in juvenile dwarf mongooses (Helogale undulata rufula). Animal Behaviour, 32, 579-589.

RENNER, M. J. (1990). Neglected aspects of exploratory and investigative behavior. Psychobiology, 18, 16-22.

RESENDE, B. D.; OTTONI, E. B. (2002). Brincadeira e aprendizagem do uso de ferramentas em macacos-prego (Cebus apella). Estudos de Psicologia (Natal), v. 7, p. 173-180.

RESENDE, B. D. (2003). Some observations on the predation of small mammals by tufted capuchin monkeys (Cebus sp.). Neotropical Primates, v. 11, n. 2, p. 103.

RESENDE, B. D. (2004). Ontogenia de comportamentos manipulativos em um grupo de macacos-prego (Cebus apella) em situação de semiliberdade. Tese de doutorado apresentada no Instituto de Psicologia da Universidade de São Paulo. 
RESENDE, B. D.; IZAR, P. \& OTTONI, E. B. (2004). Social play and spatial tolerance in tufted capuchin monkeys (Cebus apella). Revista de Etologia, 6(1): 55-61.

RESENDE, B. D.; OTTONI, E. B. \& FRAGASZY, D. M. (2008). Ontogeny of manipulative behavior and nut-cracking in young tufted capuchin monkeys (Cebus apella): a perception-action perspective. Developmental Science, 11(6): 828-840.

RIDLEY, M. (2003). Nature via nurture: Genes, experience, and what makes us human. HarperCollins.

RYLANDS, A. B. (2000). An Assesment of the Diversity of New World Primates. Neotropical Primates 8 (2): 61-93.

SALES, M. C. L. (2003). Degradação Ambiental Em Gilbués, PI. Mercator Revista de Geografia da UFC, n. 4, p. 1-19.

SILVA, V. P. R. (2004). On climate variability in Northeast of Brazil. Journal of Arid Environments, v.58, n.4, p.575 - 596.

SMITH, S.M. (1983). The ontogeny of avian behavior. In: Farner, D.S., King, J.R. and Parkes, K.C. (eds) Avian biology. Vol. 7; New York; Academic Press: 85-160.

SINGH, S., BARTO, A. G., \& CHENTANEZ, N. (2005). Intrinsically motivated reinforcement learning. In Advances in neural information processing systems 17: Proceedings of the 2004 conference. Cambridge MA: MIT Press.

SKINNER, B.F.(1953). Ciência e Comportamento Humano. São Paulo: Martins Fontes, 1998, 10ª ed. 
SPAGNOLETTI, N.; VISALBERGHI, E.; OTTONI E.; IZAR P.; FRAGASZY D. (2011a). Stone tool use in wild bearded capuchin monkeys, Cebus libidinosus. Is it a strategy to overcome food scarcity? American Journal of Primatology 73:1-17.

SPAGNOLETTI, N.; VISALBERGHI, E.; OTTONI E.; IZAR P.; FRAGASZY D. (2011b). Stone tool use by adult wild bearded capuchin monkeys (Cebus libidinosus). Frequency, efficiency and tool selectivity. Journal of Human Evolution. Volume 61, Issue 1, July 2011, Pages 97-107.

SPAGNOLETTI, N.; VISALBERGHI, E.; VERDERANE, M.; OTTONI, E.; IZAR, P.; FRAGASZY, D. (2012). Stone tool use in wild bearded capuchin monkeys, Cebus libidinosus. Is it a strategy to overcome food scarcity? Anim Beh 83:1285-1294.

STEPHENS, D. W. (1993). Learning and behavioral ecology: incomplete information and environmental predictability. In: Papaj, D.R. \& Lewis, A.C. (Eds) Insect learning. New York; Chapman \& Hall: 195-218, 1993.

STRICK P. L., DUM R. P., FIEZ J. A. (2009). Cerebellum and nonmotor function. Annual Rev. Neuroscience. 32, 413-434.

TERBORGH, J. (1983). Five new world primates. Princeton: Princeton University Press.

TOMASELLO, M. \& CALL, J. (1997). Primate Cognition. Oxford University Press, Oxford.

TORONCHUK J. A., ELLIS G.F. (2012) Affective neuronal selection: the nature of the primordial emotion systems. Front Psychol. Jan 9;3:589. doi: 10.3389/fpsyg.2012.00589. eCollection, 
VISALBERGHI, E., FRAGASZY, D., OTTONI, E., IZAR, P., DE OLIVEIRA, M.G., ANDRADE, F.R.D., (2007). Characteristics of hammer stones and anvils used by wild bearded capuchin monkeys (Cebus libidinosus) to crack open palm nuts. Am. J. Phys. Anthropol. 132, 426e444.

VISALBERGHI, E., SPAGNOLETTI, N., RAMOS DA SILVA, E.D., DE ANDRADE, F.R., OTTONI, E., IZAR, P., FRAGASZY, D., (2009a). Transport of hammer tools and nuts by wild capuchin monkeys. Primates 50, 95e104.

VISALBERGHI, E., ADDESSI, E., TRUPPA, V., SPAGNOLETTI, N., OTTONI, E., IZAR, P., FRAGASZY, D., (2009b). Selection of effective stone tools by wild capuchin monkeys. Curr. Biol. 19, 213e217.

VERDERANE, M. P. (2005). Estilos de cuidado materno e desenvolvimento das relações sociais de infantes de macacos-prego, Cebus apella, de 0 a 18 meses de idade. Dissertação de mestrado apresentada no Instituto de Psicologia da Universidade de São Paulo.

VERDERANE, M. P. (2010). Socioecologia de macacos-prego (Cebus libidinosus) em área de ecótono Cerrado/Caatinga. Tese de doutorado apresentada no Instituto de Psicologia da Universidade de São Paulo.

VON HOFSTEN, C (2009). Action, the foundation for cognitive development. Scandinavian Journal of Psychology. Volume 50, Issue 6, pages 617-623.

WALLEN, K. (1996). Nature needs nurture: the interaction of hormonal and social influences on the development of behavioral sex differences in rhesus monkeys. Horm. Behav.;30:364-378.

WALLEN, K. (2005). Hormonal influences on sexually differentiated behavior in nonhuman primates. Frontiers in neuroendocrinology, 26(1), 7-26. 
WALTERS, J. (1987). Transition to adulthood. En B.B. Smuts; R. M. Seyfarth; R. M. Wrangham; T.T. Struhsaker (Orgs.), Primate Societies. Chicago: University of Chicago Press.

WATTS, D. P.; PUSEY, A. E. (1993). Behavior of juvenile and adolescent great apes. Juvenile primates: Life history, development, and behavior, p. 148170, 1993.

WAGA, I.C., DACIER, A.K., PINGA, P.S., TAVARES, M.C.H., (2006). Spontaneous tool use by wild capuchin monkeys (Cebus libidinosus) in the cerrado. Folia Primatol. 77, 337e344.

WELKER, C.; HÖHMANN, H.; SCHÄFER-WITT, C.; ZUR. (1989). Ontogenese der Geschlechterrollen bei dem gehaubten Kapuziner Cebus apella (Ontogeny of sex roles in the black-capped capuchin Cebus apella). Homo 39:26-34.

WILSON, M. (2002). Six views of embodied cognition. Psychonomic Bulletin \& Review, 9 (4), 625-636.

WINANDY, M. (2012). O período juvenil em macacos-prego: ontogenia das relações sociais e do forrageamento. Dissertação de Mestrado apresentada no Instituto de Psicologia da Universidade de São Paulo.

WINKLER, H. \& LEISLER, B. (1999). Exploration and curiosity in birds: Functions and mechanisms. In: Adams, N.J. \& Slotow, R.H. (eds) Proc. 22 Int. Ornithology Congress, Durban: 915-932. Johannesburg: BirdLife, South Africa.

WISE, R. A. (2004). Dopamine, learning and motivation. Nat. Rev. 5, 483494. doi: $10.1038 / \mathrm{nrn} 1406$. 
ANEXOS

Anexo 1: Resultados Completos de testes de correlação não-paramétrica

\begin{tabular}{|c|c|c|}
\hline \multirow[t]{2}{*}{ Amostra: } & Variáveis utilizadas para testar correlação: & \\
\hline & \multicolumn{2}{|l|}{ Brincadeira Social x Manipulação } \\
\hline \multirow[t]{5}{*}{ BV1 (todos indivíduos) } & & Resultados \\
\hline & Coeficiente de Spearman $(r s)=$ & 0,6909 \\
\hline & $t=$ & 2,8671 \\
\hline & $(p)=$ & $0,0185 \quad *$ \\
\hline & Número de pares $=$ & 11 \\
\hline \multirow[t]{5}{*}{ BV2 (todos os indivíduos) } & & Resultados \\
\hline & Coeficiente de Spearman $(\mathrm{rs})=$ & 0,028 \\
\hline & $t=$ & 0,0885 \\
\hline & $(p)=$ & 0,9312 \\
\hline & Número de pares $=$ & 12 \\
\hline \multirow[t]{5}{*}{ PET (todos os indivíduos) } & & Resultados \\
\hline & Coeficiente de Spearman $(\mathrm{rs})=$ & $-0,1105$ \\
\hline & $t=$ & $-0,4585$ \\
\hline & $(p)=$ & 0,6524 \\
\hline & Número de pares $=$ & 19 \\
\hline \multirow[t]{5}{*}{ BV1 (Machos) } & & Resultados \\
\hline & Coeficiente de Spearman $(\mathrm{rs})=$ & 0,6 \\
\hline & $t=$ & 1,5 \\
\hline & $(p)=$ & 0,2079 \\
\hline & Número de pares $=$ & 6 \\
\hline BV1 (Fêmeas) & & Resultados \\
\hline
\end{tabular}




\begin{tabular}{|c|c|c|}
\hline & Coeficiente de Spearman $(\mathrm{rs})=$ & 0,2 \\
\hline & $t=$ & 0,3536 \\
\hline & $(p)=$ & 0,7471 \\
\hline & Número de pares = & 5 \\
\hline \multirow[t]{5}{*}{ BV2 (Machos) } & & Resultados \\
\hline & Coeficiente de Spearman (rs) = & 0,2857 \\
\hline & $t=$ & 0,6667 \\
\hline & $(p)=$ & 0,5345 \\
\hline & Número de pares = & 7 \\
\hline \multirow[t]{5}{*}{ BV2 (Fêmeas) } & & Resultados \\
\hline & Coeficiente de Spearman $(r s)=$ & 0,8 \\
\hline & $t=$ & 2,3094 \\
\hline & $(p)=$ & 0,104 \\
\hline & Número de pares = & 5 \\
\hline \multirow[t]{5}{*}{ PET (Machos) } & & Resultados \\
\hline & Coeficiente de Spearman (rs) = & $-0,3407$ \\
\hline & $t=$ & $-1,2017$ \\
\hline & $(p)=$ & 0,2546 \\
\hline & Número de pares $=$ & 13 \\
\hline \multirow[t]{5}{*}{ PET (Fêmeas) } & & Resultados \\
\hline & Coeficiente de Spearman $(r s)=$ & 0,6571 \\
\hline & $t=$ & 1,7436 \\
\hline & $(p)=$ & 0,1561 \\
\hline & Número de pares $=$ & 6 \\
\hline \multirow[t]{2}{*}{ Amostra: } & Comportamentos: & \\
\hline & Brincadeira Social x Percussão & o coco \\
\hline BV1 (todos os indivíduos) & & Resultados \\
\hline
\end{tabular}




\begin{tabular}{|c|c|c|}
\hline & Coeficiente de Spearman $(\mathrm{rs})=$ & $-0,4364$ \\
\hline & $t=$ & $-1,4549$ \\
\hline & $(p)=$ & 0,1796 \\
\hline & Número de pares = & 11 \\
\hline \multirow[t]{5}{*}{ BV2 (todos os indivíduos) } & & Resultados \\
\hline & Coeficiente de Spearman (rs) = & 0,473 \\
\hline & $t=$ & 1,6979 \\
\hline & $(p)=$ & 0,1203 \\
\hline & Número de pares = & 12 \\
\hline \multirow[t]{5}{*}{ PET (todos os indivíduos) } & & Resultados \\
\hline & Coeficiente de Spearman $(r s)=$ & $-0,275$ \\
\hline & $t=$ & $-1,1793$ \\
\hline & $(p)=$ & 0,2545 \\
\hline & Número de pares = & 19 \\
\hline \multirow[t]{5}{*}{ BV1 (Machos) } & & Resultados \\
\hline & Coeficiente de Spearman (rs) = & 0,3143 \\
\hline & $t=$ & 0,6621 \\
\hline & $(p)=$ & 0,5441 \\
\hline & Número de pares $=$ & 6 \\
\hline \multirow[t]{5}{*}{ BV1 (Fêmeas) } & & Resultados \\
\hline & Coeficiente de Spearman $(r s)=$ & $-0,9$ \\
\hline & $t=$ & $-3,5762$ \\
\hline & $(p)=$ & 0,0374 \\
\hline & Número de pares $=$ & 5 \\
\hline \multirow[t]{5}{*}{ BV2 (Fêmeas) } & & Resultados \\
\hline & Coeficiente de Spearman (rs) = & 0,5345 \\
\hline & $t=$ & 1,4142 \\
\hline & $(p)=$ & 0,2164 \\
\hline & Número de pares $=$ & 7 \\
\hline
\end{tabular}




\begin{tabular}{|c|c|c|}
\hline \multicolumn{3}{|l|}{ BV2 (Fêmeas) } \\
\hline & -----dados insuficientes **----- & \\
\hline \multirow[t]{5}{*}{ PET (Machos) } & & Resultados \\
\hline & Coeficiente de Spearman $(r s)=$ & $-0,0706$ \\
\hline & $t=$ & $-0,2347$ \\
\hline & $(p)=$ & 0,8187 \\
\hline & Número de pares $=$ & 13 \\
\hline \multirow[t]{5}{*}{ PET (Fêmeas) } & & Resultados \\
\hline & Coeficiente de Spearman $(r s)=$ & $-0,5409$ \\
\hline & $t=$ & $-1,2862$ \\
\hline & $(p)=$ & 0,2677 \\
\hline & Número de pares $=$ & 6 \\
\hline \multirow[t]{2}{*}{ Amostra: } & Comportamentos: & \\
\hline & \multicolumn{2}{|c|}{ Brincadeira Social $x$ Quebra proficiente } \\
\hline \multirow[t]{5}{*}{ BV1 (todos os indivíduos) } & & Resultados \\
\hline & Coeficiente de Spearman $(r s)=$ & 0,0286 \\
\hline & $t=$ & 0,0858 \\
\hline & $(p)=$ & 0,9335 \\
\hline & Número de pares $=$ & 11 \\
\hline \multirow[t]{5}{*}{ BV2 (todos os indivíduos) } & & Resultados \\
\hline & Coeficiente de Spearman $(r s)=$ & 0,5322 \\
\hline & $t=$ & 1,9878 \\
\hline & $(p)=$ & 0,0748 \\
\hline & Número de pares $=$ & 12 \\
\hline
\end{tabular}




\begin{tabular}{|c|c|c|}
\hline \multirow[t]{5}{*}{ PET (todos os indivíduos) } & & Resultados \\
\hline & Coeficiente de Spearman $(r s)=$ & $-0,2084$ \\
\hline & $t=$ & $-0,8785$ \\
\hline & $(p)=$ & 0,3919 \\
\hline & Número de pares $=$ & 19 \\
\hline \multirow[t]{5}{*}{ BV1 (Machos) } & & Resultados \\
\hline & Coeficiente de Spearman $(r s)=$ & 0,116 \\
\hline & $t=$ & 0,2335 \\
\hline & $(p)=$ & 0,8268 \\
\hline & Número de pares = & 6 \\
\hline \multirow[t]{5}{*}{ BV1 (Fêmeas) } & & Resultados \\
\hline & Coeficiente de Spearman $(r s)=$ & $-0,7826$ \\
\hline & $t=$ & $-2,1776$ \\
\hline & $(p)=$ & 0,1176 \\
\hline & Número de pares = & 5 \\
\hline \multirow[t]{5}{*}{ BV2 (Machos) } & & Resultados \\
\hline & Coeficiente de Spearman $(r s)=$ & 0,6682 \\
\hline & $t=$ & 2,008 \\
\hline & $(p)=$ & 0,1008 \\
\hline & Número de pares $=$ & 7 \\
\hline \multicolumn{3}{|l|}{ BV2 (Fêmeas) } \\
\hline & -----dados insuficientes ${ }^{\star *}$ & \\
\hline \multirow[t]{3}{*}{ PET (Machos) } & & Resultados \\
\hline & Coeficiente de Spearman (rs) = & $-0,0067$ \\
\hline & $t=$ & $-0,0223$ \\
\hline
\end{tabular}




\begin{tabular}{|l|l|l|}
\hline & $(\mathrm{p})=$ & 0,9826 \\
\hline & Número de pares = & 13 \\
\hline & & \\
\hline PET (Fêmeas) & & Resultados \\
\hline & Coeficiente de Spearman $(\mathrm{rs})=$ & $-0,5409$ \\
\hline & $\mathrm{t}=$ & $-1,2862$ \\
\hline & $(\mathrm{p})=$ & 0,2677 \\
\hline & Número de pares $=$ & 6 \\
\hline
\end{tabular}

${ }^{*} p<0,05$

${ }^{* *}$ Amostra pequena para realizar o teste

Anexo 2: Comparações de médias entre machos e fêmeas de BV1, BV2 e PET em relação às frequências relativas (FR) de "Manipulação".

\begin{tabular}{|c|c|}
\hline \multicolumn{2}{|l|}{ Amostras: } \\
\hline \multicolumn{2}{|c|}{ Machos e Fêmeas de BV1 e BV2 (mesmo grupo em duas fases de coleta) } \\
\hline \multicolumn{2}{|l|}{ Resultado: } \\
\hline FRmachosBV2 > FRmachosBV1 & FRfemeasBV2 > FRfemeasBV1 \\
\hline Wilcoxon Test & Wilcoxon Test \\
\hline$T=0$ & $\mathrm{~T}=0$ \\
\hline Número de pares $=6$ & Número de pares $=5$ \\
\hline$Z=-2,2014$ & $Z=-2,0226$ \\
\hline$(p)=0,0277^{*}$ & $(p)=0,0431$ * \\
\hline \multicolumn{2}{|l|}{ Amostras: } \\
\hline \multicolumn{2}{|l|}{ Machos e Fêmeas de BV1 e PET } \\
\hline \multicolumn{2}{|l|}{ Resultado: } \\
\hline FRmachosPET > FRmachosBV1 & FRfemeasPET > FRfemeasBV1 \\
\hline Mann-Whitney Test & Mann-Whitney Test \\
\hline $\mathrm{n} 1=6$ & $\mathrm{n} 1=5$ \\
\hline $\mathrm{n} 2=13$ & $\mathrm{n} 2=6$ \\
\hline
\end{tabular}




\begin{tabular}{|c|c|}
\hline $\mathrm{R} 1=21$ & $\mathrm{R} 1=15$ \\
\hline $\mathrm{R} 2=169$ & $\mathrm{R} 2=51$ \\
\hline$U=0$ & $U=0$ \\
\hline$Z(U)=3,4205$ & $Z(U)=2,7386$ \\
\hline (p) $=0,0006^{*}$ & $(p)=0,0062 *$ \\
\hline \multicolumn{2}{|l|}{ Amostras: } \\
\hline \multicolumn{2}{|l|}{ Machos e Fêmeas de BV2 e PET } \\
\hline \multicolumn{2}{|l|}{ Resultado: } \\
\hline FRmachosBV2 > FRmachosPET & FRfemeasBV2 = FRfemeasPET \\
\hline Mann-Whitney Test & Mann-Whitney Test \\
\hline $\mathrm{n} 1=7$ & $\mathrm{n} 1=5$ \\
\hline $\mathrm{n} 2=13$ & $\mathrm{n} 2=6$ \\
\hline $\mathrm{R} 1=48$ & $\mathrm{R} 1=25$ \\
\hline $\mathrm{R} 2=162$ & $\mathrm{R} 2=41$ \\
\hline$U=20$ & $U=10$ \\
\hline$Z(U)=2,0207$ & $Z(U)=0,9129$ \\
\hline (p) $=0,0433$ * & $(p)=0,3613$ \\
\hline \multicolumn{2}{|l|}{ Amostras: } \\
\hline \multicolumn{2}{|l|}{ BV1: machos e fêmeas } \\
\hline \multicolumn{2}{|l|}{ Resultado: } \\
\hline \multicolumn{2}{|l|}{ Machos manipularam mais } \\
\hline \multicolumn{2}{|l|}{ Mann-Whitney Test } \\
\hline \multicolumn{2}{|l|}{$\mathrm{n} 1=6$} \\
\hline \multicolumn{2}{|l|}{$\mathrm{n} 2=5$} \\
\hline \multicolumn{2}{|l|}{$\mathrm{R} 1=48$} \\
\hline \multicolumn{2}{|l|}{$\mathrm{R} 2=18$} \\
\hline \multicolumn{2}{|l|}{$U=3$} \\
\hline \multicolumn{2}{|l|}{$Z(U)=2,1909$} \\
\hline$(p)=0,0285^{*}$ & \\
\hline
\end{tabular}




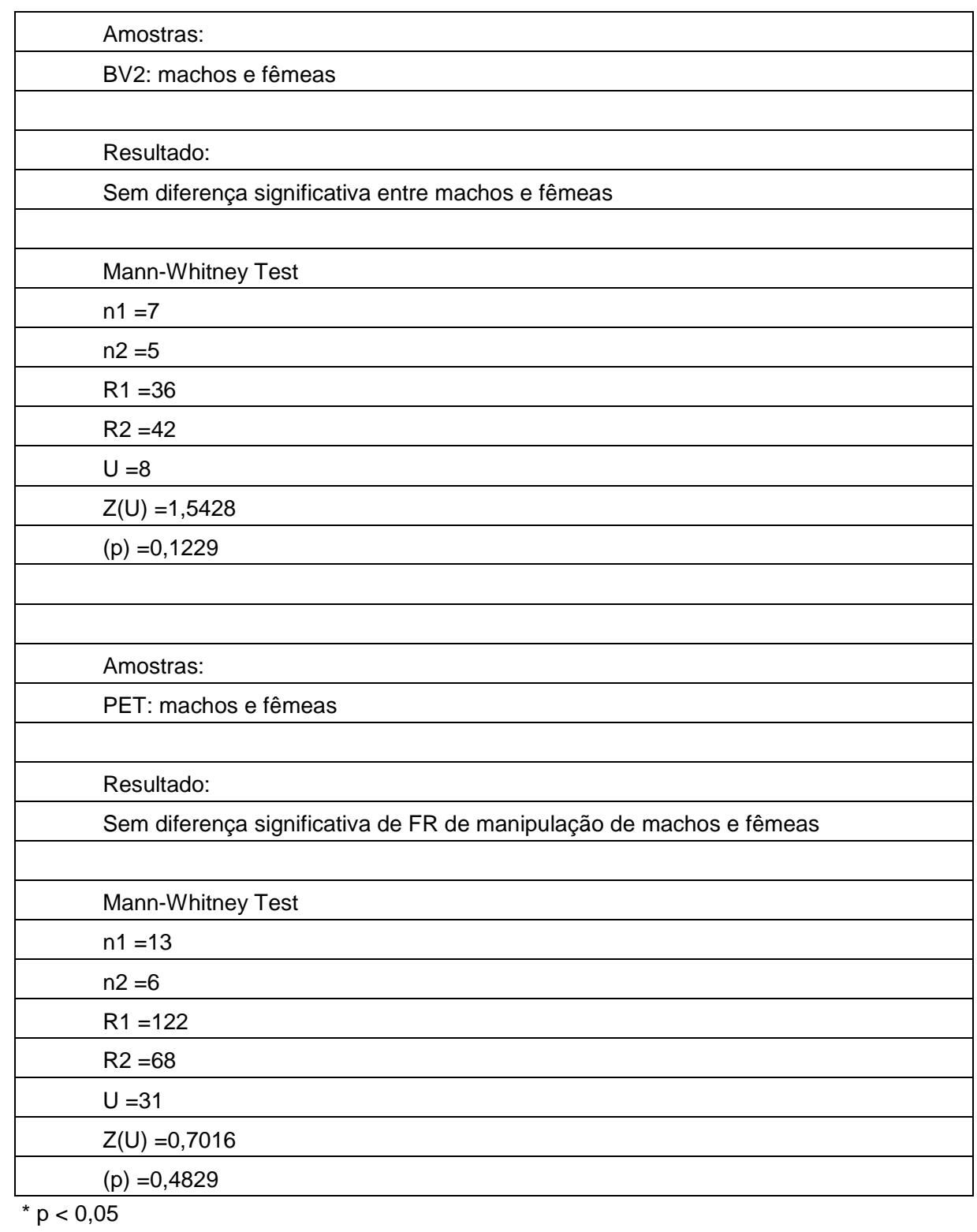

Anexo 3: Comparações de médias entre machos e fêmeas de BV1, BV2 e PET em relação às frequências relativas (FR) de "Brincadeira social"

\section{Amostras:}

Machos e Fêmeas de BV1 e BV2 (mesmo grupo em duas fases de coleta) 


\begin{tabular}{|c|c|c|}
\hline \multicolumn{3}{|l|}{ Resultado: } \\
\hline $\begin{array}{l}\text { FRmachosBV1 } \\
\text { FRmachosBV2 }\end{array}$ & $>$ & FRfemeasBV1 = FRfemeasBV2 \\
\hline Wilcoxon Test & & Wilcoxon Test \\
\hline $\mathrm{T}=1$ & & $\mathrm{~T}=1$ \\
\hline Número de pares $=6$ & & Número de pares $=5$ \\
\hline$Z=-1,9917$ & & $Z=-1,7529$ \\
\hline$(p)=0,0464^{*}$ & & $(p)=0,0796$ \\
\hline \multicolumn{3}{|l|}{ Amostras: } \\
\hline \multicolumn{3}{|c|}{ Machos e Fêmeas de BV1 e PET } \\
\hline \multicolumn{3}{|l|}{ Resultado: } \\
\hline $\begin{array}{l}\text { FRmachosPET } \\
\text { FRmachosBV1 }\end{array}$ & $>$ & FRfemeasPET = FRfemeasBV1 \\
\hline Mann-Whitney Test & & Mann-Whitney Test \\
\hline $\mathrm{n} 1=6$ & & $\mathrm{n} 1=5$ \\
\hline $\mathrm{n} 2=13$ & & $\mathrm{n} 2=6$ \\
\hline $\mathrm{R} 1=28$ & & $\mathrm{R} 1=22$ \\
\hline $\mathrm{R} 2=162$ & & $\mathrm{R} 2=44$ \\
\hline$U=7$ & & $U=7$ \\
\hline$Z(U)=2,8066$ & & $Z(U)=1,4606$ \\
\hline (p) $=0,005^{*}$ & & $(p)=0,1441$ \\
\hline \multicolumn{3}{|l|}{ Amostras: } \\
\hline \multicolumn{3}{|c|}{ Machos e Fêmeas de BV2 e PET } \\
\hline \multicolumn{3}{|l|}{ Resultado: } \\
\hline $\begin{array}{l}\text { FRmachosPET } \\
\text { FRmachosBV2 }\end{array}$ & $>$ & FRfemeasPET > FRfemeasBV2 \\
\hline Mann-Whitney Test & & Mann-Whitney Test \\
\hline $\mathrm{n} 1=7$ & & $\mathrm{n} 1=5$ \\
\hline $\mathrm{n} 2=13$ & & $\mathrm{n} 2=6$ \\
\hline $\mathrm{R} 1=28$ & & $\mathrm{R} 1=19$ \\
\hline $\mathrm{R} 2=182$ & & $\mathrm{R} 2=47$ \\
\hline$U=0$ & & $U=4$ \\
\hline
\end{tabular}




\begin{tabular}{|c|c|}
\hline$Z(U)=3,6056$ & $Z(U)=2,0083$ \\
\hline (p) $=0,0003$ * & $(p)=0,0446 *$ \\
\hline \multicolumn{2}{|l|}{ Amostras: } \\
\hline \multicolumn{2}{|l|}{ BV1: machos e fêmeas } \\
\hline \multicolumn{2}{|l|}{ Resultado: } \\
\hline \multicolumn{2}{|c|}{ Machos brincaram mais que fêmeas } \\
\hline \multicolumn{2}{|l|}{ Mann-Whitney Test } \\
\hline \multicolumn{2}{|l|}{$\mathrm{n} 1=6$} \\
\hline \multicolumn{2}{|l|}{$\mathrm{n} 2=5$} \\
\hline \multicolumn{2}{|l|}{$\mathrm{R} 1=49$} \\
\hline \multicolumn{2}{|l|}{$\mathrm{R} 2=17$} \\
\hline \multicolumn{2}{|l|}{$U=2$} \\
\hline \multicolumn{2}{|l|}{$Z(U)=2,3735$} \\
\hline \multicolumn{2}{|l|}{ (p) $=0,0176^{\star}$} \\
\hline \multicolumn{2}{|l|}{ Amostras: } \\
\hline \multicolumn{2}{|l|}{ BV2: machos e fêmeas } \\
\hline \multicolumn{2}{|l|}{ Resultado: } \\
\hline \multicolumn{2}{|c|}{ Sem diferença significativa entre machos e fêmeas } \\
\hline \multicolumn{2}{|l|}{ Mann-Whitney Test } \\
\hline \multicolumn{2}{|l|}{$\mathrm{n} 1=7$} \\
\hline \multicolumn{2}{|l|}{$\mathrm{n} 2=5$} \\
\hline \multicolumn{2}{|l|}{$\mathrm{R} 1=55$} \\
\hline \multicolumn{2}{|l|}{$\mathrm{R} 2=23$} \\
\hline \multicolumn{2}{|l|}{$U=8$} \\
\hline \multicolumn{2}{|l|}{$Z(U)=1,5428$} \\
\hline \multicolumn{2}{|l|}{ (p) $=0,1229$} \\
\hline \multicolumn{2}{|l|}{ Amostras: } \\
\hline PET: machos e fêmeas & \\
\hline
\end{tabular}




\begin{tabular}{|l|}
\hline Resultado: \\
\hline Machos brincaram mais que fêmeas \\
\hline \\
\hline Mann-Whitney Test \\
\hline $\mathrm{n} 1=13$ \\
\hline $\mathrm{n} 2=6$ \\
\hline $\mathrm{R} 1=159$ \\
\hline $\mathrm{R} 2=31$ \\
\hline$U=10$ \\
\hline $\mathrm{Z}(\mathrm{U})=2,5435$ \\
\hline$(\mathrm{p})=0,011^{*}$ \\
\hline${ }^{*} \mathrm{p}<0,05$ \\
\hline
\end{tabular}

Anexo 4: Comparações de médias entre machos e fêmeas de BV1, BV2 e PET em relação às frequências relativas (FR) de "Percussão de pedra no coco"

\begin{tabular}{|c|c|}
\hline \multicolumn{2}{|l|}{ Amostras: } \\
\hline \multicolumn{2}{|c|}{ Machos e Fêmeas de BV1 e BV2 (mesmo grupo em duas fases de coleta) } \\
\hline \multicolumn{2}{|l|}{ Resultado: } \\
\hline $\begin{array}{l}\text { FRmachosBV1 } \\
\text { FRmachosBV2 }\end{array}$ & FRfemeasBV1 = FRfemeasBV2 \\
\hline Wilcoxon Test & Wilcoxon Test \\
\hline $\mathrm{T}=0$ & $T=0$ \\
\hline Número de pares $=6$ & Número de pares $=4$ \\
\hline$Z=-2,2014$ & $Z=-1,8257$ \\
\hline (p) $=0,0277^{*}$ & $(p)=0,0679$ \\
\hline \multicolumn{2}{|l|}{ Amostras: } \\
\hline \multicolumn{2}{|c|}{ Machos e Fêmeas de BV1 e PET } \\
\hline \multicolumn{2}{|l|}{ Resultado: } \\
\hline $\begin{array}{l}\text { FRmachosBV1 } \\
\text { FRmachosPET }\end{array}$ & FRfemeasPET = FRfemeasBV1 \\
\hline Mann-Whitney Test & Mann-Whitney Test \\
\hline $\mathrm{n} 1=6$ & $\mathrm{n} 1=5$ \\
\hline
\end{tabular}




\begin{tabular}{|c|c|}
\hline $\mathrm{n} 2=13$ & $\mathrm{n} 2=6$ \\
\hline $\mathrm{R} 1=85$ & $\mathrm{R} 1=39$ \\
\hline $\mathrm{R} 2=105$ & $\mathrm{R} 2=27$ \\
\hline$U=14$ & $\mathrm{U}=6$ \\
\hline$Z(U)=2,1926$ & $Z(U)=1,6432$ \\
\hline$(p)=0,0283^{*}$ & $(p)=0,1003$ \\
\hline \multicolumn{2}{|l|}{ Amostras: } \\
\hline \multicolumn{2}{|c|}{ Machos e Fêmeas de BV2 e PET } \\
\hline \multicolumn{2}{|l|}{ Resultado: } \\
\hline $\begin{array}{l}\text { FRmachosPET } \\
\text { FRmachosBV2 }\end{array}$ & FRfemeasPET = FRfemeasBV2 \\
\hline Mann-Whitney Test & Mann-Whitney Test \\
\hline $\mathrm{n} 1=7$ & $\mathrm{n} 1=5$ \\
\hline $\mathrm{n} 2=13$ & $\mathrm{n} 2=6$ \\
\hline $\mathrm{R} 1=73$ & $\mathrm{R} 1=25$ \\
\hline $\mathrm{R} 2=137$ & $\mathrm{R} 2=41$ \\
\hline$U=45$ & $U=10$ \\
\hline$Z(U)=0,0396$ & $Z(U)=0,9129$ \\
\hline$(p)=0,9684$ & $(p)=0,3613$ \\
\hline \multicolumn{2}{|l|}{ Amostras: } \\
\hline \multicolumn{2}{|c|}{ BV1: machos e fêmeas } \\
\hline \multicolumn{2}{|l|}{ Resultado: } \\
\hline \multicolumn{2}{|c|}{ Sem diferença significativa entre machos e fêmeas } \\
\hline \multicolumn{2}{|l|}{ Mann-Whitney Test } \\
\hline \multicolumn{2}{|l|}{$\mathrm{n} 1=6$} \\
\hline \multicolumn{2}{|l|}{$\mathrm{n} 2=5$} \\
\hline \multicolumn{2}{|l|}{$\mathrm{R} 1=31$} \\
\hline \multicolumn{2}{|l|}{$\mathrm{R} 2=35$} \\
\hline \multicolumn{2}{|l|}{$U=10$} \\
\hline \multicolumn{2}{|l|}{$Z(U)=0,9129$} \\
\hline$(p)=0,3613$ & \\
\hline
\end{tabular}




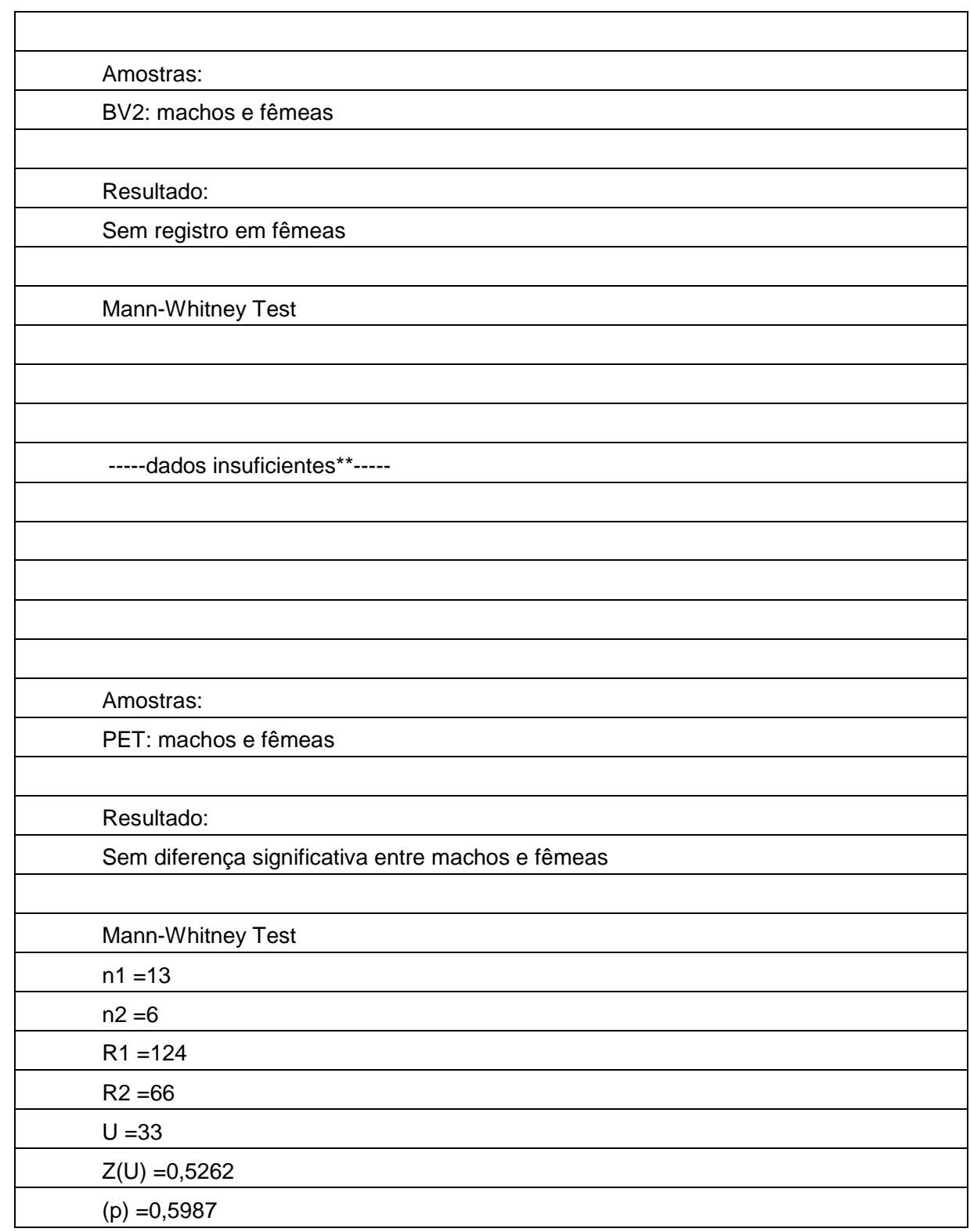

${ }^{*} \mathrm{p}<0,05$

** Amostra pequena para realizar o teste

Anexo 5: Comparações de médias entre machos e fêmeas de BV1, BV2 e PET em relação às frequências relativas (FR) de "Quebra proficiente" 


\begin{tabular}{|c|c|}
\hline \multicolumn{2}{|c|}{ Machos e Fêmeas de BV1 e BV2 (mesmo grupo em duas fases de coleta) } \\
\hline \multicolumn{2}{|l|}{ Resultado: } \\
\hline \multicolumn{2}{|c|}{ Sem diferenças significativas entre as duas coletas } \\
\hline Wilcoxon Test & Wilcoxon Test \\
\hline $\mathrm{T}=2$ & $\mathrm{~T}=0$ \\
\hline Número de pares $=4$ & Número de pares $=2$ \\
\hline$Z=-1,0954$ & $Z=-1,3416$ \\
\hline$(p)=0,2733$ & (p) $=0,1797$ \\
\hline \multicolumn{2}{|l|}{ Amostras: } \\
\hline \multicolumn{2}{|c|}{ Machos e Fêmeas de BV1 e PET } \\
\hline \multicolumn{2}{|l|}{ Resultado: } \\
\hline \multicolumn{2}{|c|}{ Sem diferenças significativas entre as duas coletas } \\
\hline Mann-Whitney Test & Mann-Whitney Test \\
\hline $\mathrm{n} 1=6$ & $\mathrm{n} 1=5$ \\
\hline $\mathrm{n} 2=13$ & $\mathrm{n} 2=6$ \\
\hline $\mathrm{R} 1=75$ & $\mathrm{R} 1=29$ \\
\hline $\mathrm{R} 2=115$ & $\mathrm{R} 2=37$ \\
\hline$U=24$ & $U=14$ \\
\hline$Z(U)=1,3156$ & $Z(U)=0,1826$ \\
\hline (p) $=0,1883$ & $(p)=0,8551$ \\
\hline \multicolumn{2}{|l|}{ Amostras: } \\
\hline \multicolumn{2}{|c|}{ Machos e Fêmeas de BV2 e PET } \\
\hline \multicolumn{2}{|l|}{ Resultado: } \\
\hline \multicolumn{2}{|c|}{ Sem diferenças significativas entre as duas coletas } \\
\hline Mann-Whitney Test & Mann-Whitney Test \\
\hline $\mathrm{n} 1=7$ & $\mathrm{n} 1=5$ \\
\hline $\mathrm{n} 2=13$ & $\mathrm{n} 2=6$ \\
\hline $\mathrm{R} 1=71,5$ & $\mathrm{R} 1=25$ \\
\hline $\mathrm{R} 2=138,5$ & $\mathrm{R} 2=41$ \\
\hline
\end{tabular}




\begin{tabular}{|c|c|}
\hline$U=43,5$ & $U=10$ \\
\hline$Z(U)=0,1585$ & $Z(U)=0,9129$ \\
\hline$(p)=0,8741$ & $(p)=0,3613$ \\
\hline \multicolumn{2}{|l|}{ Amostras: } \\
\hline \multicolumn{2}{|l|}{ BV1: machos e fêmeas } \\
\hline \multicolumn{2}{|l|}{ Resultado: } \\
\hline \multicolumn{2}{|c|}{ Sem diferença significativa entre machos e fêmeas } \\
\hline \multicolumn{2}{|l|}{ Mann-Whitney Test } \\
\hline \multicolumn{2}{|l|}{$\mathrm{n} 1=6$} \\
\hline \multicolumn{2}{|l|}{$\mathrm{n} 2=5$} \\
\hline \multicolumn{2}{|l|}{$\mathrm{R} 1=41$} \\
\hline \multicolumn{2}{|l|}{$\mathrm{R} 2=25$} \\
\hline \multicolumn{2}{|l|}{$U=10$} \\
\hline \multicolumn{2}{|l|}{$Z(U)=0,9129$} \\
\hline \multicolumn{2}{|l|}{$(p)=0,3613$} \\
\hline \multicolumn{2}{|l|}{ Amostras: } \\
\hline \multicolumn{2}{|l|}{ BV2: machos e fêmeas } \\
\hline \multicolumn{2}{|l|}{ Resultado: } \\
\hline \multicolumn{2}{|c|}{ Sem diferença significativa entre machos e fêmeas } \\
\hline \multicolumn{2}{|l|}{ Mann-Whitney Test } \\
\hline \multicolumn{2}{|l|}{$\mathrm{n} 1=7$} \\
\hline \multicolumn{2}{|l|}{$\mathrm{n} 2=5$} \\
\hline \multicolumn{2}{|l|}{$\mathrm{R} 1=50,5$} \\
\hline \multicolumn{2}{|l|}{$\mathrm{R} 2=27,5$} \\
\hline \multicolumn{2}{|l|}{$U=12,5$} \\
\hline \multicolumn{2}{|l|}{$Z(U)=0,812$} \\
\hline \multicolumn{2}{|l|}{$(p)=0,4168$} \\
\hline \multicolumn{2}{|l|}{ Amostras: } \\
\hline PET: machos e fêmeas & \\
\hline
\end{tabular}




\begin{tabular}{|l|}
\hline \\
\hline Resultado: \\
\hline Sem diferença significativa entre machos e fêmeas \\
\hline \\
\hline Mann-Whitney Test \\
\hline $\mathrm{n} 1=13$ \\
\hline $\mathrm{n} 2=6$ \\
\hline $\mathrm{R} 1=126$ \\
\hline $\mathrm{R} 2=64$ \\
\hline $\mathrm{U}=35$ \\
\hline $\mathrm{Z}(\mathrm{U})=0,3508$ \\
\hline$(\mathrm{p})=0,7257$ \\
\hline$* \mathrm{P}<0,05$ \\
\hline
\end{tabular}

${ }^{*} p<0,05$ 